\title{
Optimal Design and Effective Control of TAME Production Process using Integrated Reactive Dividing Wall and Pressure Swing Columns
}

Dol:

10.1021/acs.iecr.7b03459

\section{Document Version}

Accepted author manuscript

Link to publication record in Manchester Research Explorer

Citation for published version (APA):

Yang, A., Lv, L., Shen, W., Dong, L., Li, J., \& Xiao, X. (2017). Optimal Design and Effective Control of TAME Production Process using Integrated Reactive Dividing Wall and Pressure Swing Columns. Industrial and Engineering Chemistry Research, 0, 14565-14581. https://doi.org/10.1021/acs.iecr.7b03459

Published in:

Industrial and Engineering Chemistry Research

\section{Citing this paper}

Please note that where the full-text provided on Manchester Research Explorer is the Author Accepted Manuscript or Proof version this may differ from the final Published version. If citing, it is advised that you check and use the publisher's definitive version.

\section{General rights}

Copyright and moral rights for the publications made accessible in the Research Explorer are retained by the authors and/or other copyright owners and it is a condition of accessing publications that users recognise and abide by the legal requirements associated with these rights.

\section{Takedown policy}

If you believe that this document breaches copyright please refer to the University of Manchester's Takedown Procedures [http://man.ac.uk/04Y6Bo] or contact uml.scholarlycommunications@manchester.ac.uk providing relevant details, so we can investigate your claim.

\section{OPEN ACCESS}




\section{Optimal Design and Effective Control of TAME Production Process} using Integrated Reactive Dividing Wall and Pressure Swing Columns yang ao, Liping Lv, Weifeng Shen, Lichun Dong, Jie Li, and Xin Xiao

Ind. Eng. Chem. Res., Just Accepted Manuscript • DOI: 10.1021/acs.iecr.7b03459 • Publication Date (Web): 17 Nov 2017

Downloaded from http://pubs.acs.org on November 29, 2017

\section{Just Accepted}

"Just Accepted" manuscripts have been peer-reviewed and accepted for publication. They are posted online prior to technical editing, formatting for publication and author proofing. The American Chemical Society provides "Just Accepted" as a free service to the research community to expedite the dissemination of scientific material as soon as possible after acceptance. "Just Accepted" manuscripts appear in full in PDF format accompanied by an HTML abstract. "Just Accepted" manuscripts have been fully peer reviewed, but should not be considered the official version of record. They are accessible to all readers and citable by the Digital Object Identifier (DOI $\left.{ }^{\circ}\right)$. "Just Accepted" is an optional service offered to authors. Therefore, the "Just Accepted" Web site may not include all articles that will be published in the journal. After a manuscript is technically edited and formatted, it will be removed from the "Just Accepted" Web site and published as an ASAP article. Note that technical editing may introduce minor changes to the manuscript text and/or graphics which could affect content, and all legal disclaimers and ethical guidelines that apply to the journal pertain. ACS cannot be held responsible for errors or consequences arising from the use of information contained in these "Just Accepted" manuscripts. 


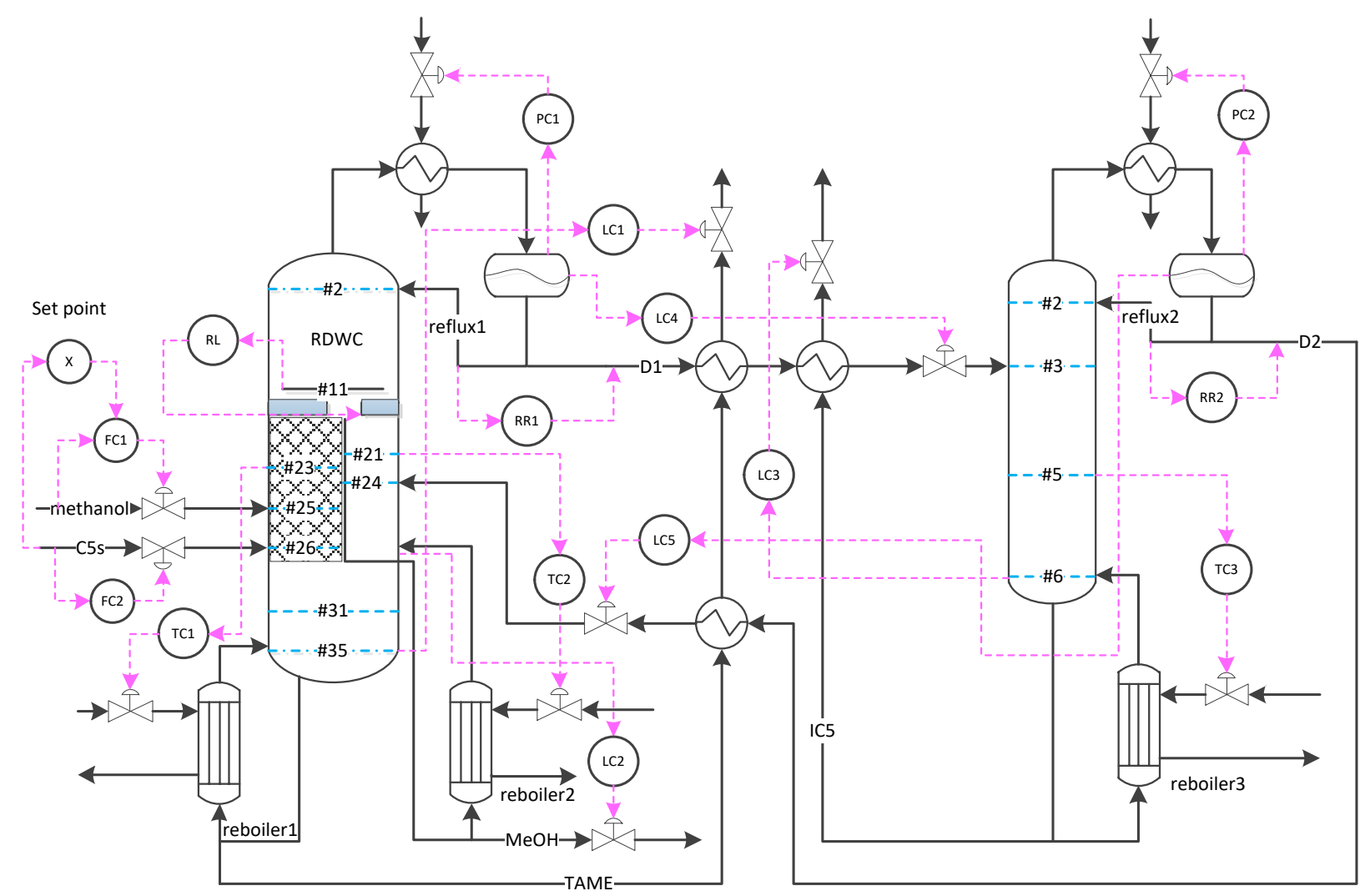




\section{Optimal Design and Effective Control of TAME Production Process using Integrated}

\section{Reactive Dividing Wall and Pressure Swing Columns}

Ao Yang ${ }^{1}$, Liping $\mathrm{Lv}^{2,3,4}$, Weifeng Shen ${ }^{1, *}$, Lichun Dong ${ }^{1}, \mathrm{Jie} \mathrm{Li}^{5}{ }^{5}$ Xin Xiao ${ }^{6}$

${ }^{1}$ School of Chemistry and Chemical Engineering, Chongqing University, Chongqing 400044, China

${ }^{2}$ School of Chemistry and Chemical Engineering, Yangtze Normal University, Chongqing, Fuling 408100, PR China

${ }^{3}$ Collaborative Innovation Center for Green Development in Wuling Moutain Area, Yangtze Normal University

${ }^{4}$ Research Center for Environmental Monitoring, Hazard Prevention of Three Gorges Reservoir, Yangtze Normal University, Fuling 408100, Chongqing, China

${ }^{5}$ School of Chemical Engineering and Analytical Science, The University of Manchester, Manchester, UK

${ }^{6}$ Division of Environment Technology and Engineering, Institute of Process Engineering, Chinese Academy of Sciences, Beijing, 100190 P. R. China

"Corresponding author:

E-mail: shenweifeng@,cqu.edu.cn 


\begin{abstract}
Design of Tert-Amyl Methyl Ether (TAME) production process has received much attention because TAME is an important oxygenated gasoline additive with much fewer environmental and health issues than Methyl Tert-Butyl Ether. Although reactive dividing wall column where reaction and separation take place in one vessel has been developed with less capital and operating cost, little work on its application to TAME production has been reported. In this paper, we propose a new overall procedure for optimal design of TAME production process through integrated reactive dividing wall and pressure swing columns, which includes screening of best dividing wall configuration, thermodynamic feasible insight, and process simulation and optimization using sensitivity analysis tool in Aspen Plus ${ }^{\circledR}$. The computational results demonstrate the optimal design of TAME production process through integrated reactive dividing wall and pressure swing columns is successfully obtained to achieve desired TAME purity of $99.958 \mathrm{~mol} \%$, significantly reducing the total annualized cost by $43.58 \%$ and decreasing the exergy loss by $48.24 \%$ compared to the existing TAME production process using reactive distillation. Finally, an effective control strategy including tray temperature control is proposed to ensure the operating conditions are well controlled at or close to their set-points in a desired time when disturbances occur.
\end{abstract}

Keywords: TAME, reactive dividing-wall column, conceptual design, control, optimization, exergy loss 


\section{INTRODUCTION}

Tert-Amyl Methyl Ether (abbreviated as TAME), a member of oxygenated fuel additive family, has received much more attention from both academia and chemical industries because of its high octane number. ${ }^{1-12}$ It is also reported that TAME could significantly help gasoline lower its Reid vapor pressure, thus reducing gasoline losses from evaporation especially in summer. ${ }^{3-4}$ More importantly, TAME could help reduce exhaust emissions of some volatile organic compounds. Therefore, it is now used as an ecologic octane-enhancing agent in the reformulated gasoline to replace Methyl Tert-Butyl Ether (MTBE) which is found to cause serious environmental and health issues. $^{3,4}$

Conventionally, TAME is produced by reacting 2-methyl-1-butene, 2-methyl-2-butene with methanol in a tubular reactor. The reaction is reversible and hence limited by chemical reaction equilibrium. To increase the productivity of TAME, a large excess of one reactant (e.g., 2-methyl-1-butene, 2-methyl-2-butene, or methanol) is often used, resulting in its surplus in reactor effluent. The effluent from the reactor is then sent to the downstream separation system consisting of one or several distillation columns to purify TAME with required specifications of gasoline additives. The unreacted reactant is recycled back to the reactor. ${ }^{3-4}$ In these conventional processes, reaction and separation usually take place in different vessels which are linked together through material and energy streams. This may leads to high capital cost. ${ }^{3-4}$ In addition, the reaction conversion is limited by chemical equilibrium, resulting in low conversion of TAME. The large surplus of unreacted reactant has to be separated from TAME to achieve high purity of TAME and recycle back, increasing the difficulty on separation and resulting in high operating cost. ${ }^{3-4}$

To overcome the above disadvantages of conventional TAME production processes, several significant efforts ${ }^{3-4,13-14,34-35}$ have been made for the development of reactive distillation, which integrates reaction and separation together into a single vessel, significantly reducing capital cost. More important, TAME is continuously removed from the reaction zone through distillation, which 
breaks the chemical equilibrium and hence increases the TAME conversion greatly. Subawalla and Fair $(1999)^{15}$ designed a prereactor and solid-catalyzed reactive distillation column for TAME production. Al-Arfaj et al. (2004) $)^{3}$ reported a synthesis and control of a plant-wide flowsheet using reactive distillation for TAME production. Although many advantages using reactive distillation are achieved, reactive distillation is only applicable to such systems with similar operating conditions (e.g., pressure and temperature) of reaction and separation which are integrated into a single vessel. Unreacted materials have to be recycled back to the feed via pipelines, still requiring a bit high capital cost and large installation spaces.

Dividing wall column (DWC) technology, ${ }^{16-23}$ one of the most important process intensification and integration approaches, has been developed to integrate two different separation units into one shell, resulting in significant reduction in both capital and operating costs and savings in required installation spaces. ${ }^{16-23}$ Numerous efforts have been reported to implement DWC technology into reactive distillation for the development of reactive dividing-wall column (RDWC) where reaction, separation, and material recycle take place in one vessel. Kiss et al. $(2009)^{24}$ highlighted that RDWC has a highly integrated configuration consisting of one condenser, one reboiler, reactive zones, a pre-fractionator and the main column in a single shell. Besides the main advantage of high conversion for reversible reactions, the use of RDWC could reduce both capital and operating cost further. ${ }^{25-28}$ Nevertheless, little work on the application of RDWC to TAME production has been reported. The only one reported effort is from Bumbac et al. (2007), ${ }^{27}$ who carried out a rough and short study on TAME production using RDWC through a simple simulation without thorough investigation of the effect of column internals such as liquid and vapor split ratio and other key design parameters such as pressure, reflux ratio, feed stages, and heat duty on product specifications. Hence no optimal design of RDWC is generated for TAME production. Furthermore, the recovery of methanol is not considered, increasing the operating cost.

To the best of our knowledge, very few efforts have been reported for TAME production and 
methanol recovery using RDWC and pressure swing distillation. Therefore, we first propose a new TAME production and methanol recovery process using integrated RDWC and pressure swing distillation. Then, a systematic procedure is proposed for optimal design and effective control of such new proposed TAME production and methanol recovery process. We first present a detailed comparative analysis on different DWC configurations based on thermodynamic characteristics of the feed for TAME production to select the best suitable DWC configuration. Then, the effect of swing pressures on reactive distillation in RDWC and pressure swing columns is evaluated through thermodynamic insight and residue curve maps to provide valuable insights on process feasibility and valid separation constraints. After that, we conduct simultaneous optimization of the integrated RDWC and pressure swing columns through sensitivity analysis tool implemented in Aspen Plus ${ }^{\circledR}$ for optimal design of the proposed integrated process. The optimal design is then evaluated through TAC and exergy loss and compare with the existing TAME production process using reactive distillation to demonstrate the advantages using RDWC. The results indicate the optimal design of TAME production process through integrated RDWC and pressure swing columns can achieve desired TAME purity of $99.958 \mathrm{~mol} \%$ with significant reduction of the total annualized cost by $43.58 \%$ and decrease of the exergy loss by $48.24 \%$ compared to the existing TAME production process using reactive distillation. Finally, a special control strategy based on tray temperature is proposed to ensure optimal design parameters are controlled at (or close to) their set-points in a desired time when disturbances occur.

\section{TAME PRODUCTION PROCESSES}

TAME is catalytically produced in the liquid phase by reacting isoamylenes 2-methyl-1-butene (2M1B) and 2-methyl-2-butene (2M2B) with methanol (MeOH). There are three main equilibrium reactions including two etherification reactions (i.e., reactions 1 and 2) and one isomerization (i.e., reaction 3). These three reactions take place simultaneously. The etherification reactions are typically limited by chemical equilibrium. 
$2 \mathrm{M} 2 \mathrm{~B}+\mathrm{MeOH} \leftrightharpoons \mathrm{TAME} \quad$ etherification

$2 \mathrm{M} 1 \mathrm{~B} \leftrightharpoons 2 \mathrm{M} 2 \mathrm{~B}$

isomerization

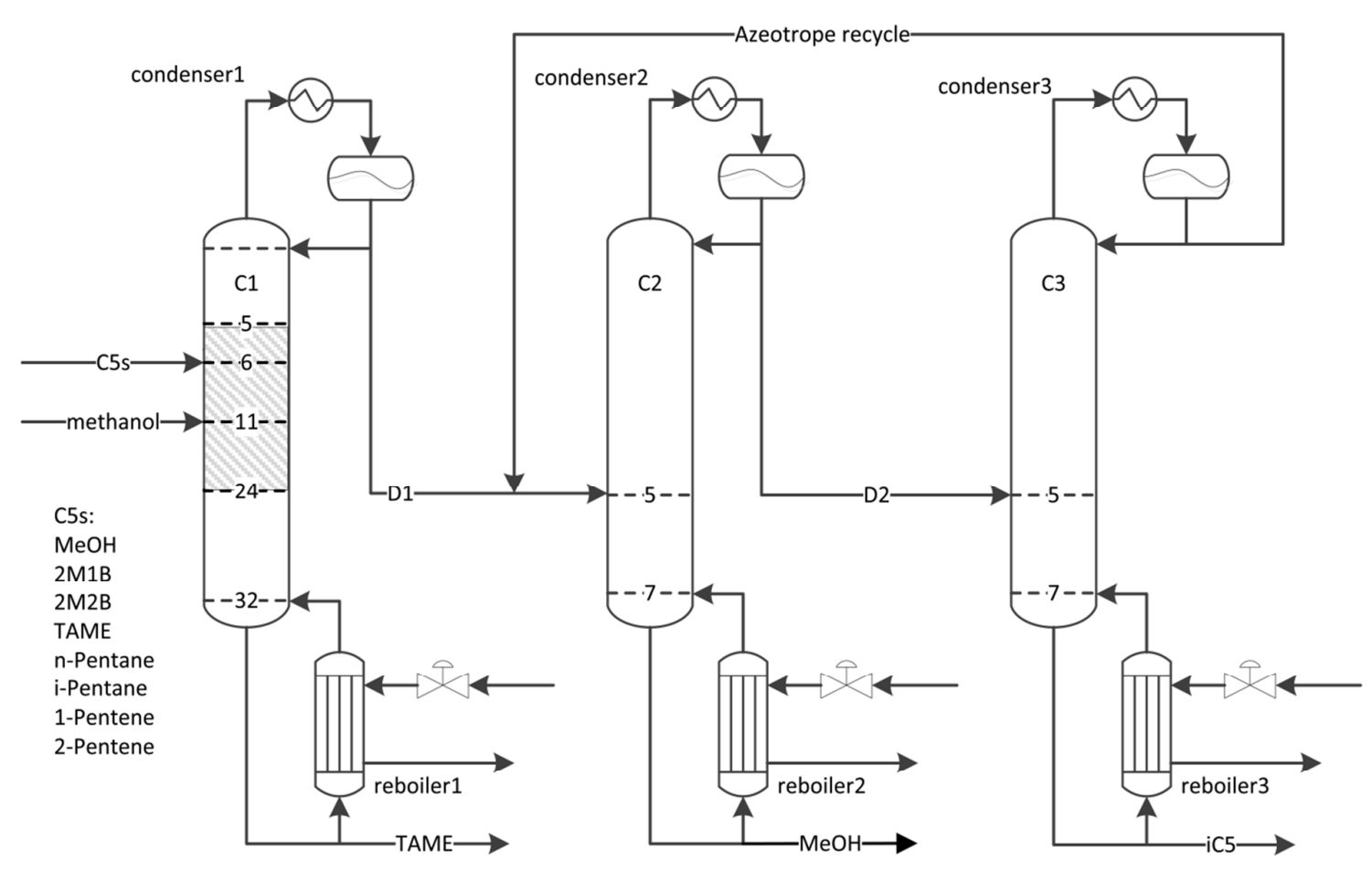

Figure 1. The existing TAME process using reactive distillation and pressure-swing column.

Figure 1 depicts the existing TAME production process through reactive distillation and pressure swing distillation, which has been studied by Al-Arfaj and Luyben. ${ }^{3-4}$ As illustrated in Figure 1, $\mathrm{C} 1$ is the reactive distillation column, whilst $\mathrm{C} 2$ and $\mathrm{C} 3$ are two distillation columns with swing pressures. There are two streams fed into $\mathrm{C} 1$. While one feed is $\mathrm{C} 5$ mixture consisting of 2M1B, 2M2B, TAME, methanol (denoted as $\mathrm{MeOH}$ ), and some unreacted compounds (e.g., n-pentane, i-pentane, 1-pentene, and 2-pentene) feeding at stage 6, the other is recycled methanol feeding at stage 11 . The bottom product of $\mathrm{C} 1$ is TAME with high purity of $99.2 \mathrm{~mol} \%$ and the top product is the unreacted methanol and iC5 mixture which is fed into $\mathrm{C} 2$ for methanol recovery. As reported $^{3-4}$, methanol and iC5 form an azeotrope, which is highly sensitive to pressure changes. 
Therefore, different pressures are used in $\mathrm{C} 2$ and $\mathrm{C} 3$ to achieve methanol separation from the iC5 mixture. The high-purity methanol of $99.9 \mathrm{~mol} \%$ is obtained at the bottom of $\mathrm{C} 2$. The top product from $\mathrm{C} 2$ is fed into $\mathrm{C} 3$ for further separation. The $\mathrm{iC} 5$ and methanol azeotrope from the top of $\mathrm{C} 3$ is recycled back to $\mathrm{C} 2$ and mixed together with the top product from $\mathrm{C} 1$.

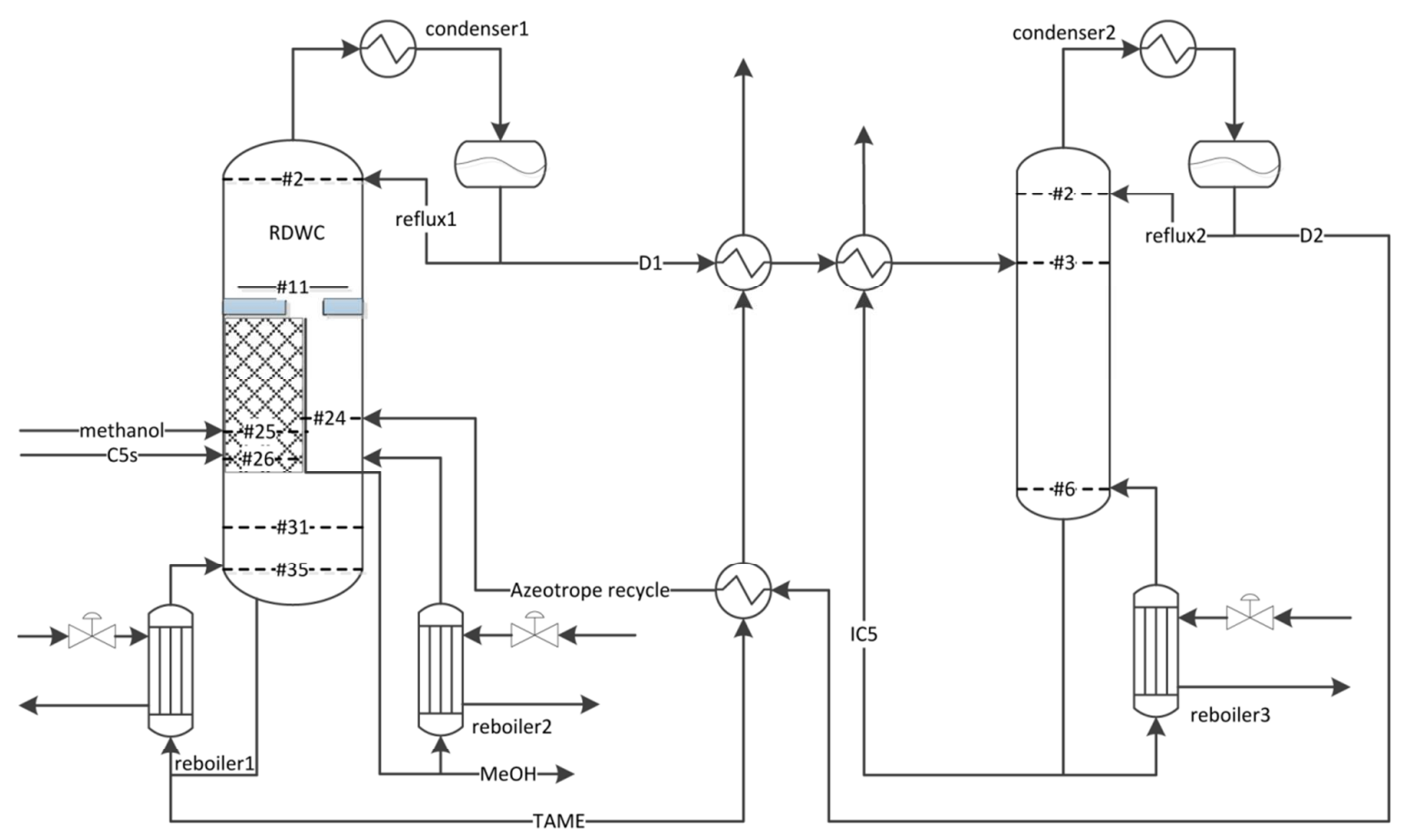

Figure 2. The proposed TAME production process using RDWC and pressure swing columns.

The proposed TAME production and methanol recovery process using integrated RDWC and pressure swing distillation is illustrated in Figure 2 where only two columns are required compared to the existing process using reactive distillation in Figure 1. The first column is RDWC, which is used for TAME production with desired purity of $99.958 \mathrm{~mol} \%$ and surplus methanol recovery. The second column is used to recover unreacted iC5 (e.g., n-pentane, i-pentane, 1-pentene, and 2-pentene). The purity of methanol reaches at most 0.001 at the bottom of the iC5 recovery column. The feed to the iC5 recovery column and the recycle azeotrope to the RDWC are heated to their desired temperature through heat exchanges with the hot bottom products of RDWC and iC5 recovery column, resulting in significant energy savings in the proposed process. 


\section{METHODOLOGY}

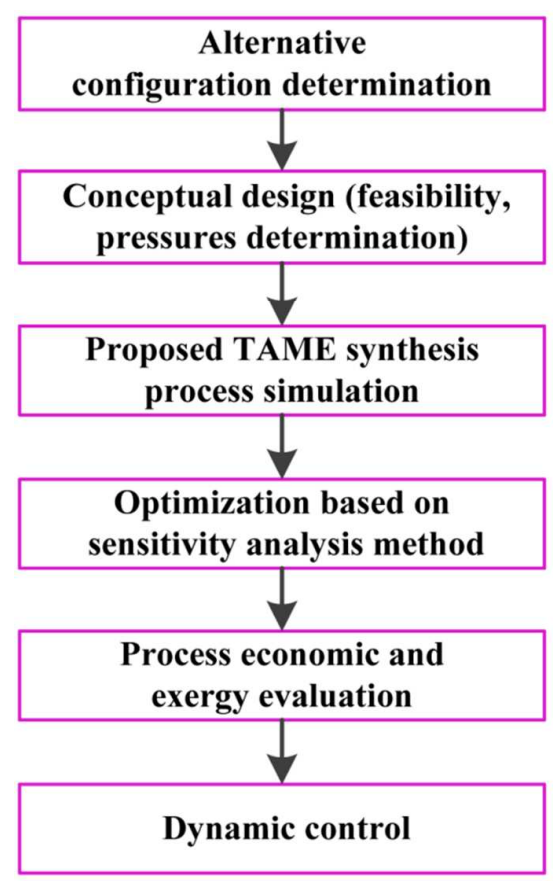

Figure 3. Proposed procedures for optimal design and effective control of TAME production process using integrated RDWC and pressure swing columns.

We propose a systematic procedure for optimal design and effective control of TAME production process through integrated RDWC and pressure-swing columns, as illustrated in Figure 3. First, several alternative DWC configurations are screened based on thermodynamic principles to select the best suitable configuration for TAME production. Then, thermodynamic insight and residue curve map analysis are conducted using Aspen SPLIT to provide valuable insights on process feasibility and offer two suitable operational pressures for RDWC and iC5 recovery column, respectively. Detailed process simulation for the proposed TAME production process based on the data from the literature ${ }^{3-4}$ is conducted in Aspen Plus ${ }^{\circledR}$ to identify lower and upper bounds of key design parameters and provide initial operational conditions for optimization, where the UNIQUAC model is chosen to calculate activity coefficients in vapor-liquid equilibrium (VLE). Following that, process optimization is performed using sensitivity analysis tool built in Aspen Plus ${ }^{\circledR}$ to obtain the optimal design including optimal operating conditions. Finally, we proposed an effective dynamic 
control strategy to ensure the system is well controlled at or close to the set-points in a desired time under the condition of disturbances.

\subsection{Dividing-Wall Configuration Determination}

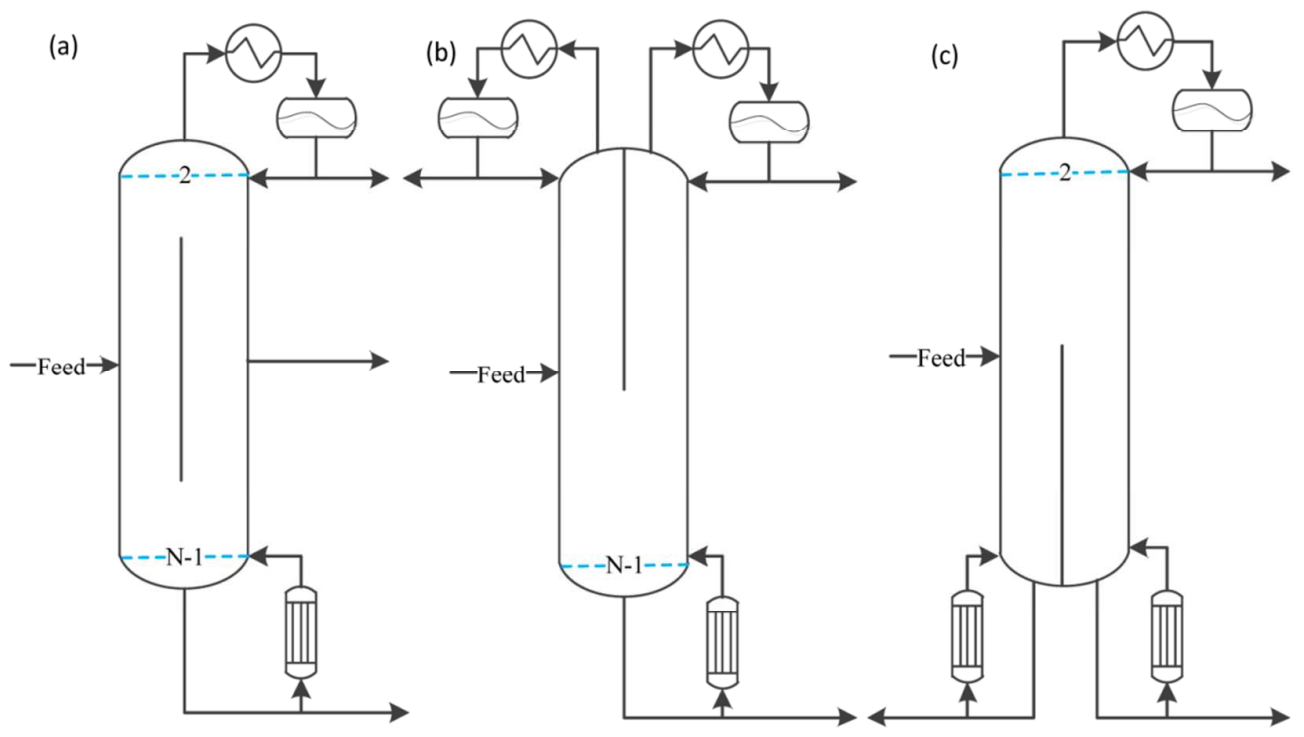

Figure 4. Three dividing-wall column configurations with a divided-wall located (a) in the middle, (b) at top, and (c) at bottom of the column.

There are three typical dividing-wall column (DWC) configurations which could be applied in the separation of multi-component or non-ideal mixtures. ${ }^{16-23}$ These configurations are illustrated in Figures 4a-4c. The DWC configuration with a divided-wall located (or close) in (to) the middle of the column (see Figure 4a) is usually designed for the separation of a ternary system without an azeotrope such as benzene-toluene-xylene. ${ }^{21}$ The DWC configuration with a divided-wall at the top of the column in Figure $4 \mathrm{~b}$ divides the column into two rectifying sections and a shared stripping section, which is often implemented in the extractive separation known as extractive DWC for the separation of an azeotropic mixture such as 2-methoxyethanol/toluene. ${ }^{22}$ The DWC configuration in Figure $4 \mathrm{c}$ involves two stripping sections and a shared rectifying section, which is often designed for the separation of a binary azeotropic mixture such as ter-butanol and water. ${ }^{16}$ The suitable configuration for this work is determined based on the unique characteristics of the system studied 
in this work.

\subsection{Thermodynamic Insight from Residue Curve Maps}

Residue curve maps (RCMs) are important graphical techniques that are often used to assist conceptual design. The RCMs can provide valuable insights on design feasibility, reveal the sensitivity of design options with a visual representation over the whole composition, and help to detect separation constraints. The ASPEN SPLIT tool that is implemented in Aspen Plus ${ }^{\circledR}$ is used to analyze RCMs of ternary and quaternary systems. The UNIQUAC model is applied for the calculation of activity coefficients in Vapor-Liquid Equilibrium (VLE).

\subsection{Reaction Kinetics}

Numerous studies on TAME production kinetics have been reported since 1990s. ${ }^{5-12}$ Most reported kinetic models are developed based on Pseudo-Homogeneous mechanism neglecting the influence of reactant adsorption. Based on this mechanism, Oktar et al. (1999) ${ }^{5}$ proposed a simple power-law kinetic model for TAME synthesis. Their model is evaluated and validated by Päivi Pääkkönen and Krause (1998) ${ }^{12}$ and Kiviranta-Pääkkönen et al. (1998). ${ }^{2}$ The proposed simple power law kinetic model from Oktar et al. (1999) 5 is given in eqs. 4-6:

$$
\begin{aligned}
& r_{1}=k_{1} \cdot e^{-\frac{E_{1}}{R T}} \cdot x_{2 \mathrm{M} 1 \mathrm{~B}} \cdot x_{\mathrm{MeOH}}-k_{1}^{\prime} \cdot e^{-\frac{E_{1}^{\prime}}{R T}} \cdot x_{\mathrm{TAME}} \\
& r_{2}=k_{2} \cdot e^{-\frac{E_{2}}{R T}} \cdot x_{2 \mathrm{M} 2 \mathrm{~B}} \cdot x_{\mathrm{MeOH}}-k_{2}^{\prime} \cdot e^{-\frac{E_{2}^{\prime}}{R T}} \cdot x_{\mathrm{TAME}} \\
& r_{3}=k_{3} \cdot e^{-\frac{E_{3}}{R T}} \cdot x_{2 \mathrm{M} 1 \mathrm{~B}}-k_{3}^{\prime} \cdot e^{-\frac{E_{3}^{\prime}}{R T}} \cdot x_{2 \mathrm{M} 2 \mathrm{~B}}
\end{aligned}
$$

where, $k_{i}$ and $k_{i}^{\prime}$ are the forward and backward preexponential factors $\left(\mathrm{kmol} \cdot \mathrm{s}^{-1} \cdot \mathrm{kg}^{-1}\right)$ for reaction $i$; $E_{i}$ and $E_{i}^{\prime}$ denote the forward and backward activation energies $\left(\mathrm{kJ} \cdot \mathrm{mol}^{-1}\right)$ for reaction $i$; $x_{j}$ stands for molar fraction of component $j$ in liquid phase; $T$ is the temperature $(\mathrm{K})$; and $R$ is the ideal gas constant $\left(\mathrm{J} \cdot \mathrm{mol}^{-1} \cdot \mathrm{K}^{-1}\right)$. Table 1 gives all kinetic parameters in eqs. $4-6 .^{3-4}$ 
Table 1. Kinetic parameters in the simple power-law model from Oktar et al. (1999) ${ }^{5}$.

\begin{tabular}{lllll}
\hline Reaction & $k_{\mathrm{i}}(\mathrm{kmol} \cdot \mathrm{s}-1 \cdot \mathrm{kg}-1 \mathrm{cat})$ & $E_{\mathrm{i}}(\mathrm{kJ} \cdot \mathrm{mol}-1)$ & $k_{\mathrm{i}}^{\prime}(\mathrm{kmol} \cdot \mathrm{s}-1 \cdot \mathrm{kg}-1 \mathrm{cat})$ & $E_{\mathrm{i}}^{\prime}(\mathrm{kJ} \cdot \mathrm{mol}-1)$ \\
\hline 1 & $1.3263 \times 108$ & 76.1034 & $2.3535 \times 1011$ & 110.5409 \\
2 & $1.3718 \times 1011$ & 98.2302 & $1.5414 \times 1014$ & 124.9940 \\
3 & $2.7187 \times 1010$ & 96.5226 & $4.2933 \times 1010$ & 104.1961 \\
\hline
\end{tabular}

Using the simple power-law kinetic model as shown in eqs. 4-6, Subawalla and Fair (1999) ${ }^{15}$ presented an iterative procedure for design of solid-catalysed reactive distillation systems including estimation of catalyst mass, reactive zone height, theoretical stages, reflux ratio, packed height, and column diameter in a reactive column. The kinetic model proposed by Oktar et al. $(1999)^{26}$ and Subawalla and Fair (1999) ${ }^{15}$ was then used for the simulation of TAME process using reactive distillation and validated by Al-Arfaj $(2004)^{3}$ and Luyben $(2009)^{4}$. In this study, we use this simple power-law model ${ }^{5}$ for TAME reaction.

\subsection{Process Simulation and Optimization}

The simulation of the proposed TAME production process is conducted in Aspen Plus ${ }^{\circledR}$ based on the simulation and optimization results for the existing TAME process using reactive distillation in the literature, ${ }^{3-4}$ and the simulation result is used to provide starting point for optimization using the sensitivity analysis tool built in Aspen Plus ${ }^{\circledR}$. Next, we introduce how the optimization model is established in this work.

3.4.1 Objective function. Total Annualized Cost (TAC) is often used as the objective function in process design such as design of extractive distillation. ${ }^{29-30}$ However, TAC usually depends on several time variant factors such as shell cost, energy price and a set of correlated variables such as the number of trays and reflux ratio. For instance, the minimum reflux ratio requires a large number of trays and vice versa. More important, the modelling of TAC introduces many nonlinear terms such as power function, increasing optimization complexities. To avoid these complexities, an alternative objective function $O F$ representing the total energy consumption per unit flow rate of products $^{29}$ is used which is defined as follows, 
$O F=f\left(N_{T 1}, N_{T 2}, N_{T 3}, R_{1}, R_{2}, N_{F 1}, N_{F 2}, N_{F E}, N_{F A}, R_{L}\right)=\frac{Q_{R 1}+Q_{R 1}^{\prime}+m \cdot Q_{C 1}+Q_{R 2}+m \cdot Q_{C 2}}{B_{1}+B_{1}^{\prime}+B_{2}}$

where, $O F$ represents energy consumption per mole of products produced $\left(\mathrm{kJ} \cdot \mathrm{kmol}^{-1}\right), Q_{R l}, Q_{R l}$, $Q_{R 2}$ and $Q_{C 1}, Q_{C 2}$ are heat duties in reboilers and condensers respectively. Energy cost difference factor, $m$, represent the difference of energy cost between the cooling water in the condenser and heating fluid in the reboiler. $B_{1}, B_{1}{ }^{\prime}$ and $B_{2}$ represent the flow rates of TAME, methanol and iC5 products, respectively, which are fixed during the optimization to avoid nonlinearity in the objective function for simplification.

3.4.2 Constraints. There are numerous significant rigorous constraints including mass balance, energy balance, thermodynamic relations, and reaction kinetics, which can be generally represented by,

$h(x)=0$

$g(x) \leq 0$

Note that all these rigorous constraints are implicitly implemented in Aspen Plus ${ }^{\circledR}$.

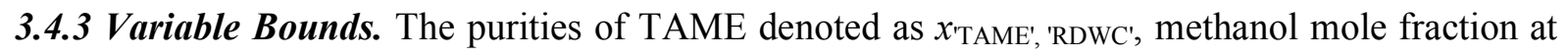

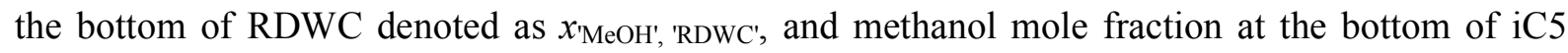
recovery column defined as $x^{\prime} \mathrm{MeOH}^{\prime}$ ' 'iC5' must meet their desired design specifications. In other words,

$x_{\text {TAME',RDWC' }} \geq 99.958 \mathrm{~mol} \%$

$x_{\text {МeOH','RDWC' }} \geq 99.9 \mathrm{~mol} \%$

$x_{\text {MeOH',ic' }} \leq 0.1 \mathrm{~mol} \%$

where, $99.958 \mathrm{~mol} \%$ is the desired TAME mole purity, $99.9 \mathrm{~mol} \%$ is the desired methanol mole fraction in methanol recycle, and $0.1 \mathrm{~mol} \%$ is the desired methanol mole fraction in the bottom 
product of iC5 column.

Lower and upper bounds on reflux ratios, liquid split ratio, total number stages of main and stripping column in RDWC, total number stages of stripping column, main feed stages, methanol feed stage, and recycle azeotropes feed stage are defined as follows,

$$
N_{T 1}^{\min } \leq N_{T 1} \leq N_{T 1}^{\max }
$$

$N_{T 2}^{\min } \leq N_{T 2} \leq N_{T 2}^{\max }$

$N_{F 1}^{\min } \leq N_{F 1} \leq N_{F 1}^{\max }$

$N_{F E}^{\min } \leq N_{F E} \leq N_{F E}^{\max }$

$N_{F A}^{\min } \leq N_{F A} \leq N_{F A}^{\max }$

$R_{1}^{\min } \leq R_{1} \leq R_{1}^{\max }$

$R_{L}^{\min } \leq R_{L} \leq R_{L}^{\max }$

$N_{F 2}^{\min } \leq N_{F 2} \leq N_{F 2}^{\max }$

$N_{T 3}^{\min } \leq N_{T 3} \leq N_{T 3}^{\max }$

$R_{2}^{\min } \leq R_{2} \leq R_{2}^{\max }$

The lower and upper bounds in eqs. 13-22 are identified by allowing some degrees of variability from the simulation results in Aspen Plus ${ }^{\circledR}$ in order to obtain the desired TAME purity, methanol mole fraction at the bottom of RDWC and methanol mole fraction at the bottom of iC5 recovery column and reduce the optimization time. Note that these lower and upper bounds may result in the elimination of some feasible region. Therefore, no global solution can be guaranteed. Our future work will develop a systematic method to identify the lower and upper bounds. 
We complete the optimization model defined as CPOM consisting of eqs. 7-22. Note that rigorous constraints (i.e., eqs. 8-9) are implicitly implemented in Aspen Plus ${ }^{\circledR}$. The sensitivity analysis tool built in Aspen Plus ${ }^{\circledR}$ is used to achieve optimal design of the proposed TAME production process in Figure 2 in order to meet desired design specifications. In the sensitivity analysis tool, the objective function is defined via "FORTR $\boldsymbol{A} N$ " function. The lower and upper bounds are defined in "Vary" function. The optimal design includes optimal reflux ratios (i.e., $R_{1}$ and $R_{2}$ in RDWC and iC5 recovery columns, respectively), optimal liquid split ratio $\left(R_{L}\right)$ in RDWC, optimal main feed stages (i.e. $N_{F 1}$ and $N_{F 2}$ in RDWC and iC5 recovery columns, respectively), optimal methanol feed stage $\left(N_{F E}\right)$, optimal recycle azeotropes feed stage $\left(N_{F A}\right)$, optimal number of stages of the main and stripping column in RDWC (i.e., $N_{\mathrm{T} 1}$ and $N_{\mathrm{T} 2}$, respectively), optimal number of stages of the stripping column (i.e., $N_{\mathrm{T} 3}$ ).

\subsection{Economic and Exergy Evaluation}

TAC is employed to evaluate the optimal design, which is calculated using the following correlation from Douglas. ${ }^{31}$

$T A C=\frac{\text { capital cost }}{\text { payback period }}+$ operating cost

where, the capital cost includes cost of column shells and heat exchangers; the operating cost mainly consists of utility cost such as cost of steam, cooling water, and electricity used in reboilers and condensers. The capital cost of pump, pipe and valves is neglected because it is much smaller compared to the capital cost of columns and heat exchangers. The operating cost of pump is also neglected because it is much smaller than that in the reboiler and condenser. ${ }^{31-32}$ The payback period is assumed to be 3 years. ${ }^{32}$

Besides economic evaluation using TAC, energy efficiency is another important indicator for design of energy-intensive RDWC process. Therefore, exergy loss is applied to evaluate the energy efficiency that could be converted to any other form of energy. ${ }^{33}$ The internal exergy loss denoted 
as $E_{l}$ is expressed using eq. 24 , which represents the difference between total input and output exergy. $^{33}$

$$
E_{l}=\sum E x_{\text {input }}-\sum E x_{\text {output }}
$$

In eq. $24, E x$ is denoted as exergy for a given system which is calculated based on enthalpy $(H)$ and entropy $(S)$ as indicated in eq. 25 :

$$
E x=\left(H-H_{0}\right)-T_{0} \cdot\left(S-S_{0}\right)
$$

where, the first term on the right hand represents the difference between the system enthalpy and that in the reference state, the second term represents the difference between the system entropy and that in the reference state, and the term $T_{0}$ is the reference temperature. In this paper, the reference state is defined as the state at the temperature of $298.15 \mathrm{~K}$ and pressure of $1 \mathrm{~atm}$.

\subsection{Dynamic Control}

Disturbances in feed flow rates and compositions often occur during the real plant operation, resulting in the deviation of the operating conditions from the optimal conditions. This may incur off-specification products and safety issues. To guarantee on-specification products and maintain safe operations, dynamic control strategies must be implemented for the RDWC and iC5 recovery columns in Figure 2. Several parameters such as feed flow rates, pressure, temperature, liquid levels, and liquid split ratio have to be controlled at or close to their set-points. However, the control of feed compositions at or close to their set-points is not easy and applicable because of their low response as well as highly expensive online measurement devices for compositions. We notice that the variation of feed compositions leads to the change of liquid compositions on each tray, which depend on tray temperature. It is also known that reboiler duty has a great effect on the tray temperatures. Therefore, in this work, the variation of tray temperatures in a column along with the changes in reboiler duty is thoroughly investigated through sensitivity analysis to determine which tray temperature should be controlled. 
1

2

3

4

5

6

7

8

10

Dynamic simulation for the controlled TAME production process is carried out using Aspen Dynamics $^{\mathrm{TM}}$ to generate system responses to disturbances in feed rates and compositions.

\section{COMPUTATIONAL RESULTS and DISCUSSIONS}

\subsection{Best Dividing-Wall Configuration}

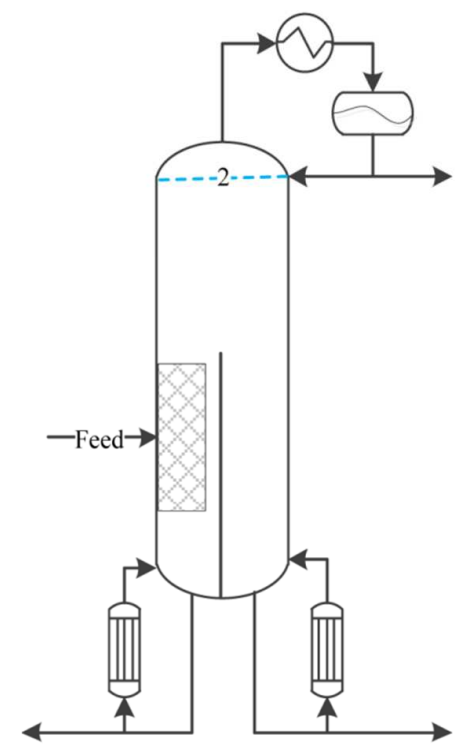

Figure 5. The best dividing-wall column configuration with an additional reactive zone and a divided-wall located at bottom section for the studied system in this work.

The feed for the proposed process includes a $\mathrm{C} 5 \mathrm{~s}$ mixture consisting of $2 \mathrm{M} 1 \mathrm{~B}, 2 \mathrm{M} 2 \mathrm{~B}$, n-pentane, i-pentane, 1-pentene, 2-pentene (cis), methanol and some TAME. Their boiling temperatures and topologic features at 1 atm are given in Table 2. From Table 2, two heavy components (i.e., methanol and TAME) are all stable nodes and other components are saddle node. First, methanol and iC5 in the mixture forms an azeotrope at $298.1 \mathrm{~K}$ and $1 \mathrm{~atm}$. Therefore, the DWC configuration in Figure $4 \mathrm{a}$ is firstly excluded due to the existence of an azeotrope in the studied system. Second, the boiling temperature of each component in the azeotropic mixture is higher than that in the feed mixture, and the temperature difference between the products on both sides of the DWC is less than $20 \mathrm{~K}$. The components including 2M1B, 2M2B, n-Pentane, i-Pentane, 
1-Pentene, 2-Pentene, methanol and TAME are stable nodes on the residue curve map. For such case, the DWC configuration with divided-wall located at the bottom of column (Figure 4c) is preferred instead of that located at top of column (Figure 4b). Overall, the DWC configuration in Figure $4 \mathrm{c}$ is the best suitable configuration for the studied system in the work. We also noted that the mixture is subject to a further reaction, resulting in the requirement of a reactive zone in the configuration. The final best DWC configuration with an additional reactive zone is illustrated in Figure 5.

Table 2. Topologic features and thermodynamic parameters in the studied system at $1 \mathrm{~atm}$.

\begin{tabular}{llll}
\hline No. & Component & Temperature $(\mathrm{K})$ & Classification \\
\hline 1 & 2M1B & 304.30 & Saddle \\
2 & 2M2B & 311.65 & Saddle \\
3 & MeOH & 337.68 & Stable node \\
4 & TAME & 359.43 & Stable node \\
5 & n-Pentane & 309.20 & Saddle \\
6 & i-Pentane & 301.00 & Saddle \\
7 & 1-Pentene & 303.20 & Saddle \\
8 & 2-Pentene & 309.49 & Saddle \\
\hline
\end{tabular}

Note: methanol and iC5 forms an azeotrope at $298.1 \mathrm{~K}$ and $1 \mathrm{~atm}$.

\subsection{Thermodynamic Insight and Residue Curve Maps}

Table 3. Topologic features of TAME chemistry and unreacted.

\begin{tabular}{lllll}
\hline Pressure (bar) & components & Singular points & Temperature (K) & composition \\
\hline 4 bar & 2M1B & Saddle & 350.45 & - \\
& 2M2B & Saddle & 358.88 & - \\
& TAME & Saddle & 413.31 & - \\
& $\mathrm{MeOH}$ & Saddle & 377.23 & - \\
& $\mathrm{iC5}$ & Saddle & 347.76 & - \\
\hline Azeotrope at 4 bar & $\mathrm{MeOH}-\mathrm{TAME}$ & Saddle & 375.88 & $\mathrm{X}_{\mathrm{MeOH}}=0.833$ \\
\cline { 2 - 5 } & $\mathrm{MeOH}-\mathrm{C} 5$ & Unstable node & 340.58 & $\mathrm{X}_{\mathrm{MeOH}}=0.256$ \\
\hline Azeotrope at 7 bar & $\mathrm{MeOH}-\mathrm{TAME}$ & Saddle & 395.61 & $\mathrm{X}_{\mathrm{MeOH}}=0.871$ \\
& $\mathrm{MeOH}-\mathrm{C} 5$ & Unstable node & 361.47 & $\mathrm{X}_{\mathrm{MeOH}}=0.303$ \\
\hline
\end{tabular}

Topologic features of TAME are shown in Table 3 and Figure 6, the normal boiling points of five pure components 2M1B, 2M2B, TAME, MeOH, and iC5 are $350.45 \mathrm{~K}, 358.88 \mathrm{~K}, 413.31 \mathrm{~K}$, $377.23 \mathrm{~K}$, and $347.76 \mathrm{~K}$ at 4 bar, respectively. Two azeotropes including MeOH-TAME and MeOH-iC5 appear at the pressure of 4 bar. The Five pure components are all saddle node and two 
azeotropes are saddle node and unstable node, respectively. All residue curves in a distillation region start from unstable nodes to stable nodes of a residue curve map. The azeotrope of $\mathrm{MeOH}$ and iC5 corresponds to an unstable node with a transforming composition of $\mathrm{MeOH}$ to be 0.256 . The other azeotrope of $\mathrm{MeOH}$ and TAME does not appear until the pressure increases to 4 bar. When the pressure increases from 4 bar to 7 bar, the transforming composition of $\mathrm{MeOH}$ increases from 0.833 to 0.871 . In other words, the influence of chemical reaction kinetics on the vapor-liquid equilibrium at 4 bar is less complex than that at 7 bar. While physical distillation boundaries may disappear, new kinetic saddle and unstable nodes may appear. As a result, the residue curve map with chemical reaction could be quite different from the physical plots, indicating that evaluating reaction kinetic effects on residue curve maps is of great importance for conceptual design of reactive distillation systems.
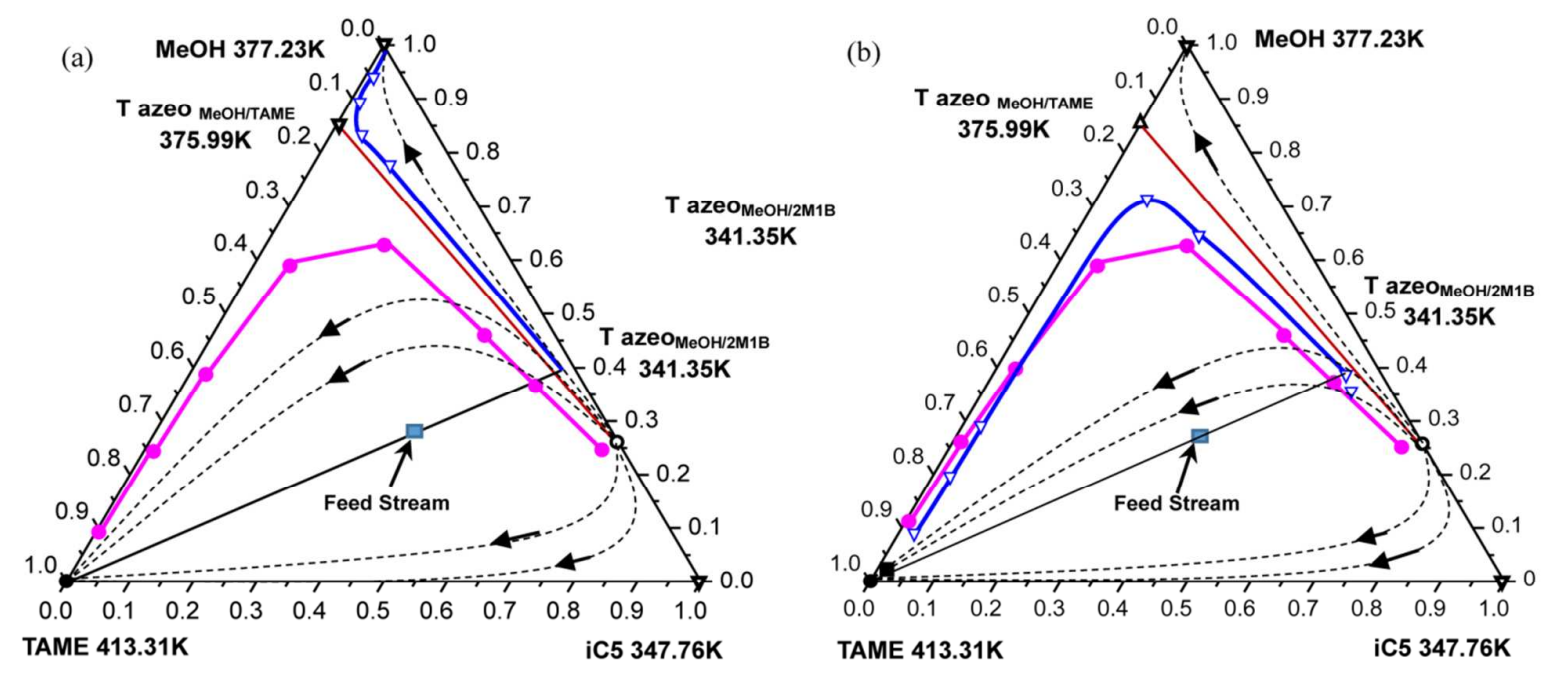

Figure 6. Residue curve maps of (a, b) ternary system at 4 bar.

Based on the above analysis, the operating pressure of 4 bar is thus chosen in this study. The residue curve maps of the ternary mixture at a pressure of 4 bar are depicted in Figures 6a and 6b, where the compositions of $\mathrm{MeOH}$ and $\mathrm{iC} 5$ at the bottom are specified as $0.001 \mathrm{~mol} \%$ and 0.01 
mol\%, respectively. When TAME composition in the distillate is specified as $5.3 \mathrm{~mol} \%$, no feasible design could be obtained because rectifying and stripping section profiles are not connected to each other, as indicated in Figure 6a. However, while TAME composition in the distillate increases to $6.0 \mathrm{~mol} \%$, a feasible design of a distillation column with 11 stages and the fifth stage to be the feed stage can be obtained. Therefore, from Figures $6 \mathrm{a}$ and $6 \mathrm{~b}$ it is clearly shown that a distillate that contains very few TAME products cannot be attained with the specified feed composition. When the feed point moves down in the diagram, the distillate point also moves down according to mass balance. It is noted that the above analysis applies to the separation of a ternary mixture without reaction. It is also indicated that adding a large excess of methanol in the reactive column may result in the loss of TAME in the overhead. Therefore, the methanol must be added in moderation for the reaction that required for the iC5/methanol azeotropes.

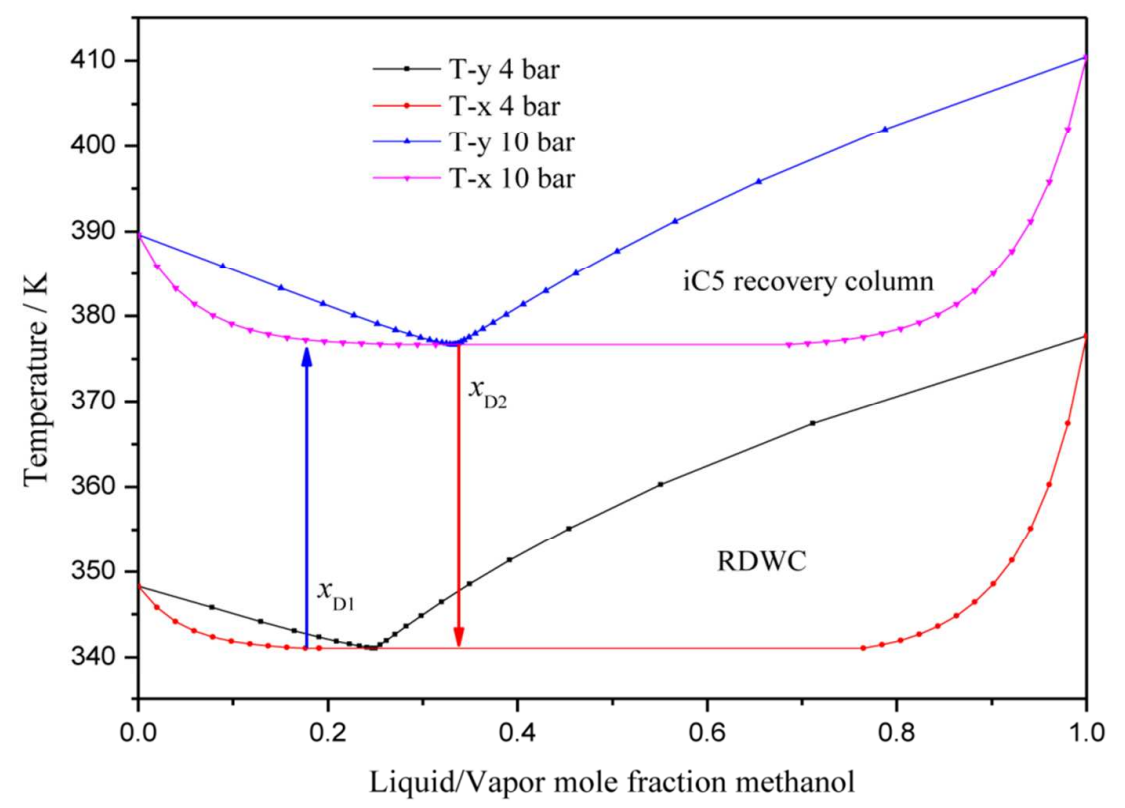

Figure 7. T-xy diagram for iC5/methanol at 4 bar and 10 bar.

The excess methanol in the mixture must be recovered and recycled back to RDWC and pre-reactor feed. The feed composition to the iC5 recovery column is close to that of the azoetrope of methanol and iC5, as shown in Figure 7 where the distillate (i.e., $x_{\mathrm{D} 1}$ ) which is from the RDWC and the feed to the iC5 column has a composition of methanol and iC5 that is close to that of the 
azeotrope at 4 bar. When the operating pressure of the iC 5 recovery column increases to 10 bar, it can be seen from Figure 7 that the azeotropic composition changes. Therefore, a pure iC5 product can be recovered from the feed in the iC5 recovery column. The azoetrope mixture in the overhead of the iC5 column is recycled back to the RDWC. If the operation pressure of iC5 recovery column is set at much lower than 10 bar, the azeotrope composition is very close to that at 4 bar, making very tough to recover iC5 from the feed in the iC5 column. Therefore, the operation pressure of the iC5 recovery column is set as 10 bar, which is identical to that of the existing process using RD.

\subsection{Process Simulation and Optimization for the Proposed TAME Production Process}

Table 4. Feed flow rates for RDWC.

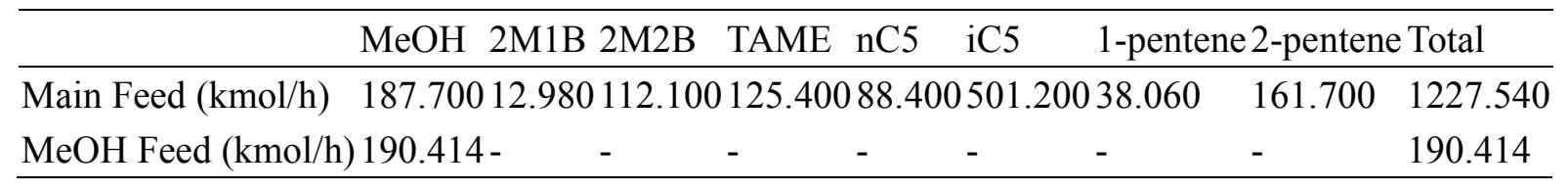

Note: Each reactive stage in RD contains $1100 \mathrm{~kg}$ of catalyst corresponding to $1.22 \mathrm{~m}^{3}$ in volume, which gives a weir height of $0.055 \mathrm{~m}$ for a reaction column with a diameter of $5.47 \mathrm{~m}$. The column operating pressure is specified at 4 bar. Catalyst bulk density is $900 \mathrm{~kg} / \mathrm{m}^{3}$. The initial values (e.g., total number of stage, feed locations, and reflux ratio) of RDWC process are set same as Al-Arfaj and Luyben $(2004)^{3}$.

The simulation and optimization are performed on the desktop with Intel Core i7-6700HQ CPU@2.60GHZ 8 GB memory. The simulation of the proposed TAME production process is conducted using the same data adapted from Al-Arfaj and Luyben (2004), ${ }^{3}$ which are given in Table 4. The desired purities of TAME and methanol in RDWC, and the methanol mole fraction at the bottom of the iC5 recovery column are respectively specified as $99.958 \mathrm{~mol} \%, 99.9 \mathrm{~mol} \%$, and 0.1 mol\% through the "Design Spec" function that is implemented in Aspen Plus ${ }^{\circledR}$ simulator. The UNIQUAC model is chosen as the thermodynamic package since there are more than two azeotropes in the reactive non-ideal mixture system. Binary parameters in the UNIQUAC model are given in Table S1 (in the Supporting Information).

Table 5. Lower and upper bounds of key design variables.

\begin{tabular}{lll}
\hline Operating variables & Lower bound & Upper bound \\
\hline Reflux ratio in RDWC & 1 & 3 \\
Reflux ratio in iC5 recovery column & 0.01 & 2 \\
\hline
\end{tabular}




\begin{tabular}{lll}
\hline Liquid split ratio & 0 & 1 \\
Methanol feed stage & 25 & 30 \\
Main feed stage 1 & 25 & 30 \\
Main feed stage 2 & 2 & 6 \\
Azeotropes recycle feed tray & 15 & 27 \\
No. of stages of main column in RDWC & 30 & 40 \\
No. of stages of stripping column in RDWC & 10 & 25 \\
No. of stages in iC5 recovery column & 6 & 10 \\
\hline
\end{tabular}

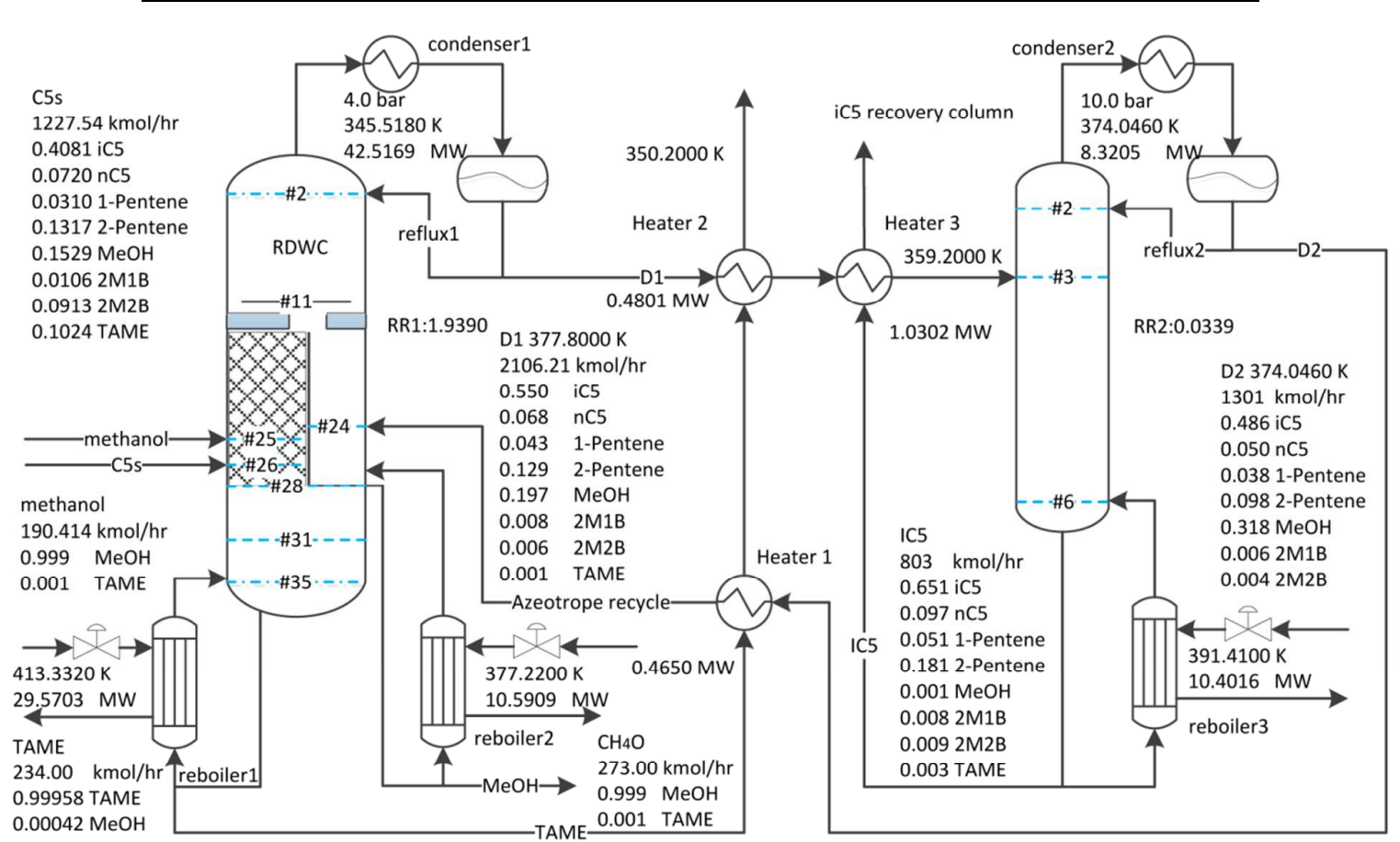

Figure 8. Optimal TAME production process using integrated RDWC and pressure swing columns.

The identified lower and upper bounds of key design variables in the model CPOM are presented in Table 5. There are total 7 discrete variables and 16 continuous variables. It takes around 6 hours for the optimization based on CPOM. The optimal TAME production process using integrated RDWC and iC5 recovery columns is illustrated in Figure 8. From Figure 8, all desired design specifications are satisfied. For instance, the TAME purity of $99.958 \mathrm{~mol} \%$ is achieved. It should be noted that the recycle methanol of $190.41 \mathrm{kmol} / \mathrm{hr}$ fed to RDWC is not equivalent to that of $273 \mathrm{kmol} / \mathrm{hr}$ produced from RDWC bottom because $83 \mathrm{kmol} / \mathrm{hr}$ methanol produced is mixed together with fresh methanol of $230.41 \mathrm{kmol} / \mathrm{hr}$ and fed to the prereactor before RDWC, which is not considered in this work. This can ensure the same conditions of the prereactor for a fair 
comparison.

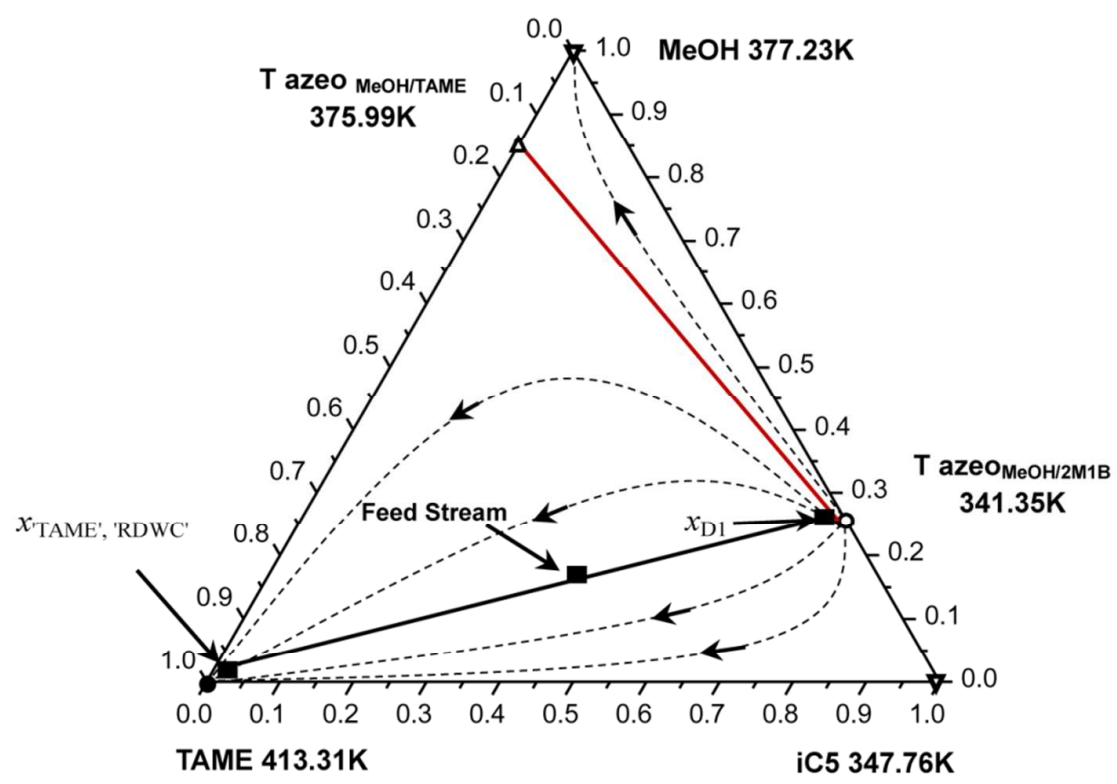

Figure 9. Residue curve maps of ternary mixtures TAME-MeOH-iC5 in RDWC.

The obtained TAME purity of $99.958 \mathrm{~mol} \%$ (i.e., $x_{\text {TAME', 'RDWC' }}=99.9580 \mathrm{~mol} \%$ ) is illustrated in Figure 9. It can be seen that the TAME purity is located in the vicinity of the TAME vertex and the terminal point of a residue curve. The obtained methanol mole fraction at the top of RDWC (denoted as $x_{\mathrm{D} 1}$ ) approaches the start point of a residue curve. The obtained methanol purities at the top of the RDWC and iC5 recovery column (i.e., $x_{\mathrm{D} 2}$ ) are $19.70 \mathrm{~mol} \%$ and $31.80 \mathrm{~mol} \%$ respectively as shown in Figure 7. From Figure 7, it is observed that $x_{\mathrm{D} 1}$ is close to the azeotropic composition at 4 bar. When the operating pressure of the iC5 recovery column increases to 10 bar, it can be seen from Figure 7 that the azeotropic composition changes, resulting in the recovery of some pure iC5 products from the feed to the iC5 column. The new azeotrope with methanol composition of 31.80 $\mathrm{mol} \%$ at the top of the iC5 recovery column is then sent back to the RDWC.

Table 6. Optimal design parameters for the proposed TAME production process.

\begin{tabular}{llll}
\hline & Optimal design parameters & Value & Unit \\
\hline RDWC & No. stages in main column, $\mathrm{N}_{\mathrm{T} 1}$ & 36 \\
& No. stages in stripping column, $\mathrm{N}_{\mathrm{T} 1}$ & 17 \\
& Main stream feed stage, $\mathrm{N}_{\mathrm{F} 1}$ & 26 \\
& Methanol feed stage, $\mathrm{N}_{\mathrm{FE}}$ & 25 \\
\hline
\end{tabular}

22 


\begin{tabular}{llll}
\hline & Azeotrope recycle feed stage, $\mathrm{N}_{\mathrm{FA}}$ & 24 & \\
& Reflux ratio, $\mathrm{R}_{1}$ & 1.9390 & \\
& Liquid split ratio, $\mathrm{R}_{\mathrm{L}}$ & 0.2974 & \\
& Wall position & $12-28$ & stages \\
& Reaction zone & $12-28$ & stages \\
& Column diameter & 6.40 & $\mathrm{~m}$ \\
\hline \multirow{2}{*}{ C5 recovery column } & No. stages in iC5 recovery column, $\mathrm{N}_{\mathrm{T} 3}$ & 7 & \\
& Main feed stage, $\mathrm{N}_{\mathrm{F} 2}$ & 3 & \\
& Reflux ratio, $\mathrm{R}_{2}$ & 0.0339 & \\
& Column diameter & 3.45 & $\mathrm{~m}$ \\
\hline
\end{tabular}

The optimal related design parameters are presented in Table 6. From Table 6 and Figure 8, it can be seen that the RDWC has total 36 stages with the reflux drum being the first stage. While the reactive zone is located at stages $12-28$ where solid acid catalyst is presented, the shared rectifying zone is from stage 2 to stage 11 . The main stream is fed into the column at stage 26 , which is located at the bottom of the reactive zone. The recycled methanol stream is fed at stage 25 , which is located at the bottom of the reactive zone. The azeotrope recycle product is fed into the stripping section at stage 24 , which is located at the bottom of stripping section. To achieve high TAME purity of $99.958 \mathrm{~mol} \%$, the optimal reflux ratio is 1.9390 and the reboiler duty for the main column is $29.5703 \mathrm{MW}$. The optimal liquid split ratio is 0.2974 , indicating that the divided wall is not located in the middle of the cross-sectional area of the column. Simultaneously, the iC5 recovery column has total 7 stages with the reflux drum as the first stage. The feed stream from the RDWC is fed to the iC5 recovery column at stage 3 with an optimal flux ratio of 0.0339 . 

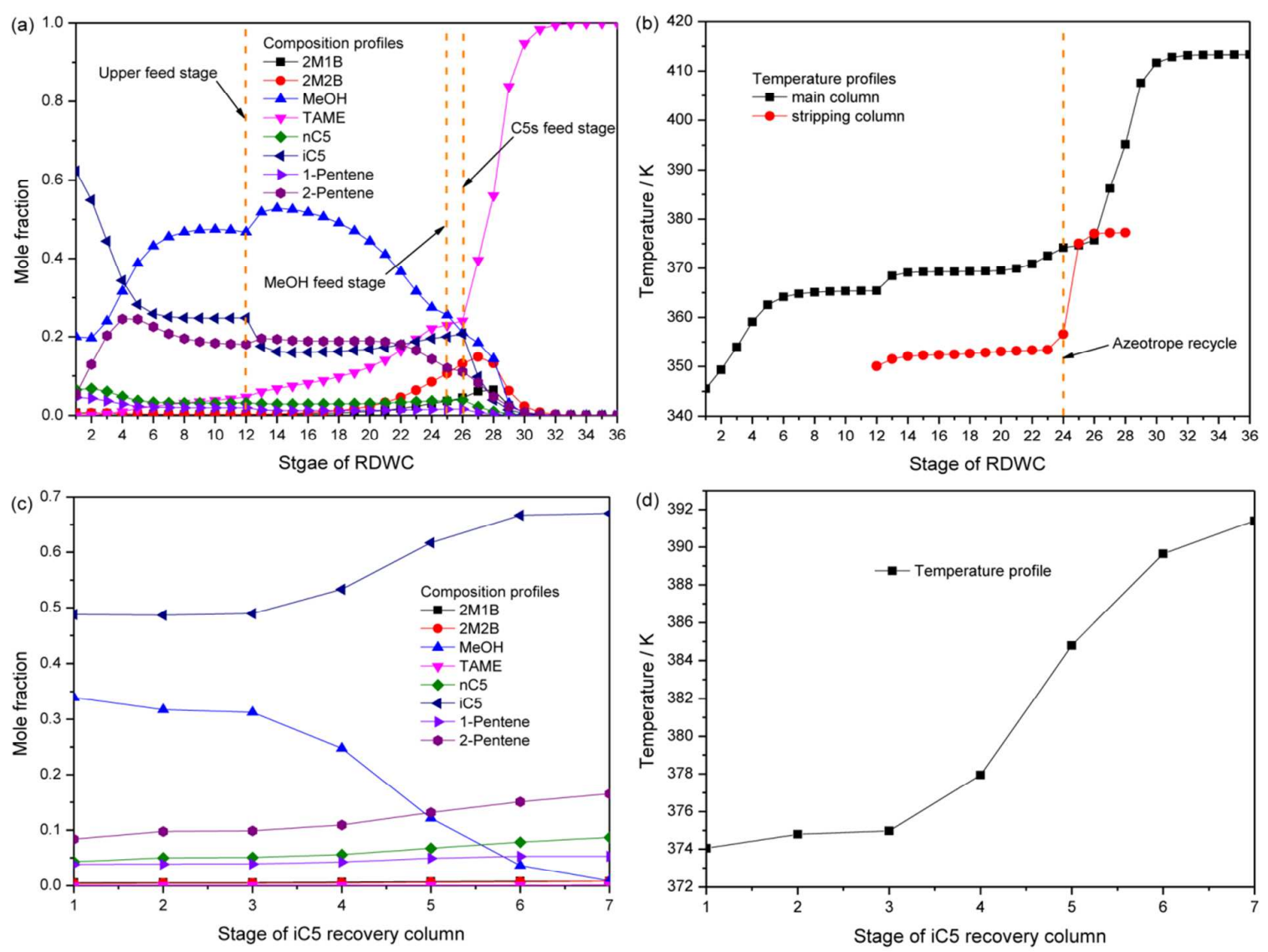

Figure 10. Liquid composition and temperature profiles in $(a, b)$ RDWC and (c, d) iC5 column.

The liquid composition and temperature profiles in the RDWC are illustrated in Figures 10a-b, respectively. From Figure 10a, it can be observed that the TAME composition increases drastically between stages 26 and 36. At stage 36, the TAME composition reaches its highest composition of $99.958 \mathrm{~mol} \%$. The TAME composition between stages 12 to 28 increases slightly with a flat gradient due to the reactions occurring in these stages. From Figure 10b, we notice that a small temperature difference between the main and stripping columns, which is less than $20 \mathrm{~K}$. The profiles exhibit sharp changes in temperature at the feed stage, which indicates the changes of liquid compositions. Major separation usually occurs at the stages with sharp temperature gradient. In Figure $10 \mathrm{~b}$, the regions with sharp temperature gradient exist in the middle of both stripping and main sections, indicating maximum separation obtained in the system.

The liquid composition and temperature profiles in the iC5 recovery column are illustrated in 
Figures 10c-d, respectively. The methanol composition decreases drastically between stages 2 and 7 . At stage 7, the methanol composition reaches its threshold mole fraction of 0.001 .

\subsection{Exergy Loss and Economic Evaluation Results}
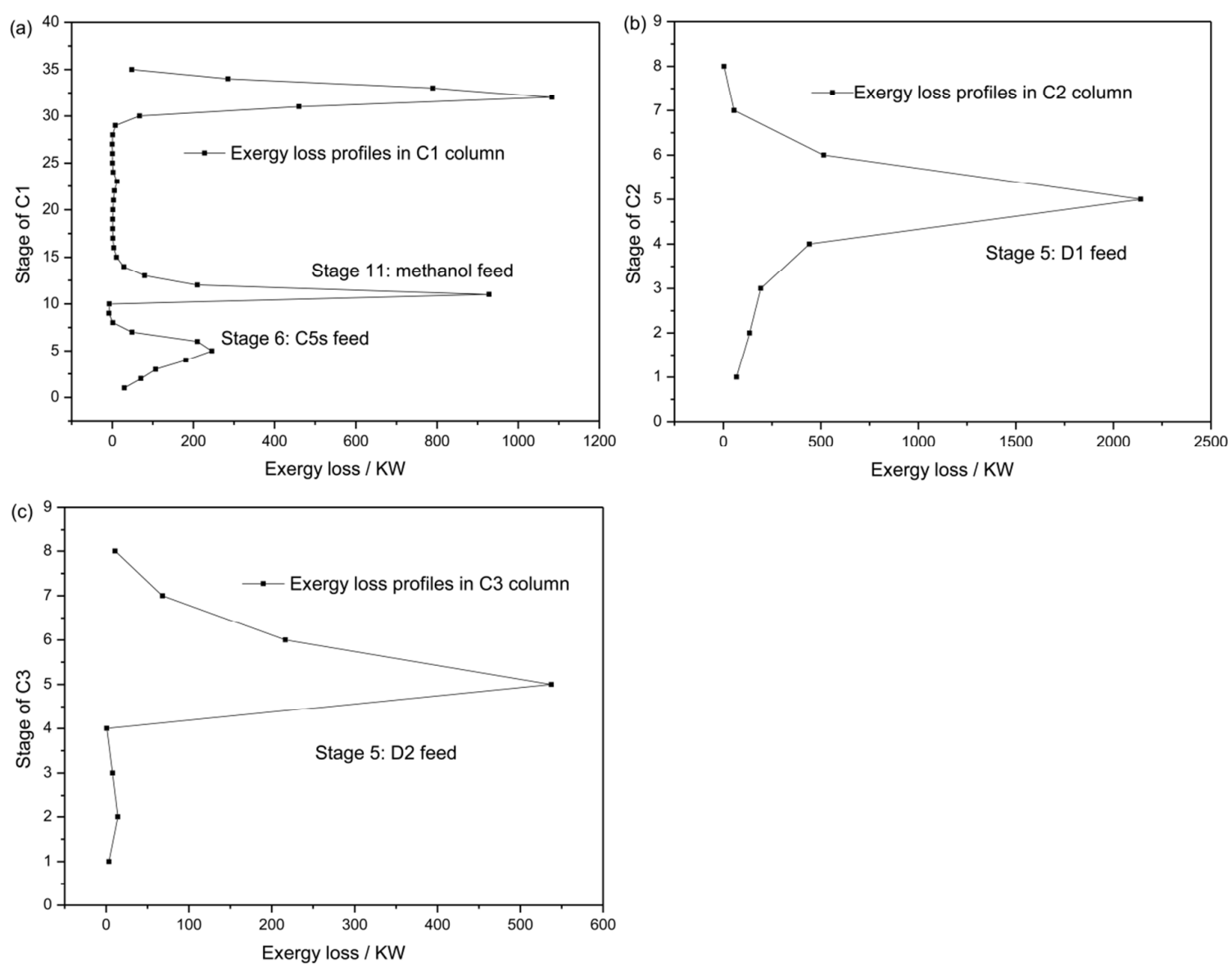

Figure 11. Exergy loss profiles in (a) $\mathrm{C} 1$ column, (b) $\mathrm{C} 2$ column, and (c) $\mathrm{C} 3$ column of the existing TAME production process using RD. 

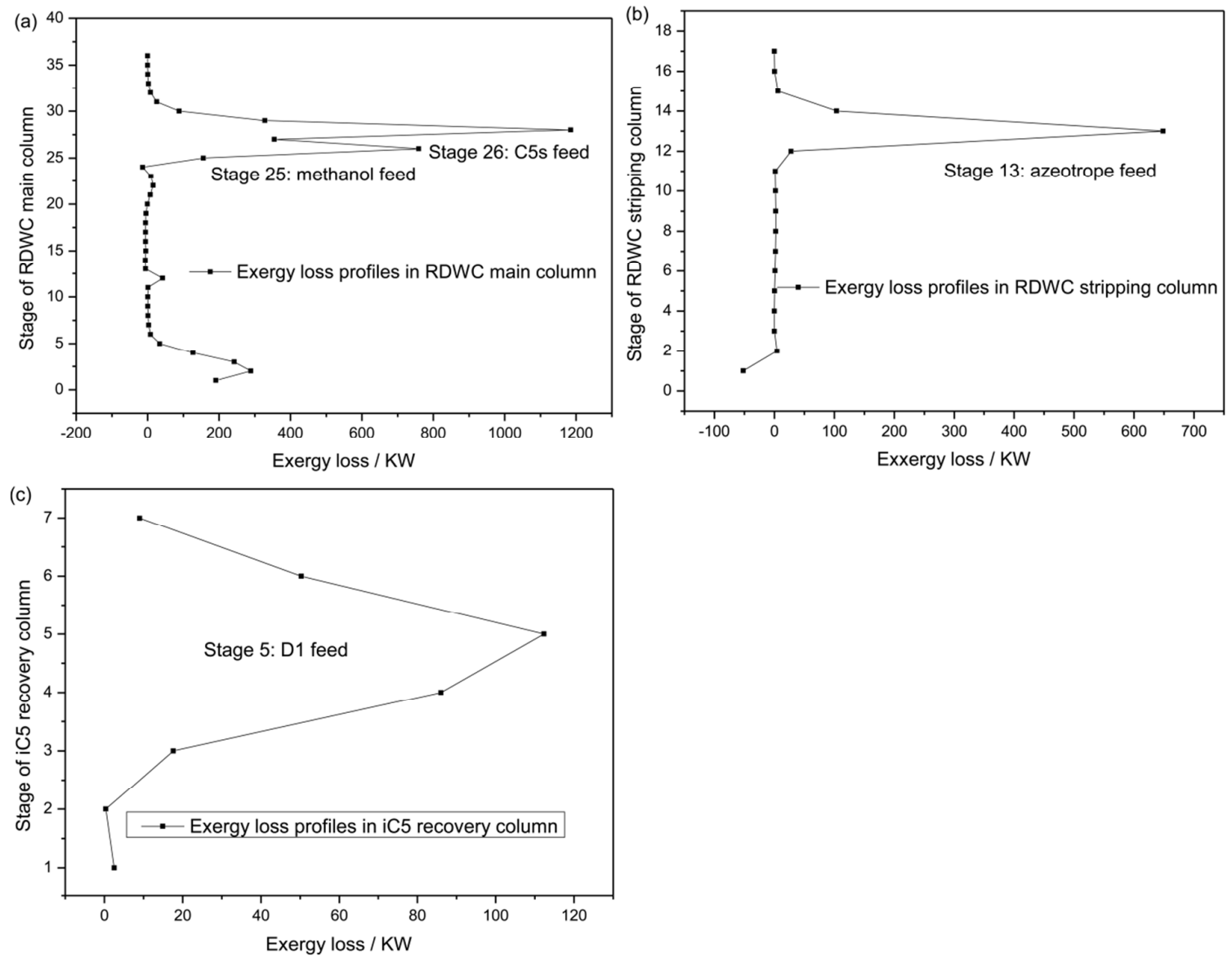

Figure 12. Exergy loss profiles in (a) main column, (b) stripping column, and (c) iC5 recovery column of the proposed TAME production process using RDWC.

The exergy loss profiles for the existing TAME production process using RD and the proposed TAME production process using RDWC are plotted in Figures 11 and 12, respectively. From Figures 11-12, it can be observed that the exergy loss profiles for both TAME production processes demonstrate that high exergy loss (see large peaks in Figures 11-12) often happens at feed stages. For instance, a high exergy loss in RD column (see Figure 11a) takes place at stages 6 and 11 where C5s and methanol are fed into the RD column. The total exergy loss in RD and RDWC columns is listed in Table 7. From Table 7, it can be observed that the exergy loss for the proposed TAME process is about 4.854 MW, compared to that of 9.378 MW for the existing TAME production process, indicating an exergy loss reduction of $48.24 \%$ using RDWC. This reduction is mainly 
contributed to the change of feed conditions by using the main column in RDWC which splits the feed into vapor stream and liquid stream.

Table 7. A head-to-head comparison of optimum design between RDWC and RD processes.

\begin{tabular}{|c|c|c|c|c|}
\hline & & & RDWC process & RD process \\
\hline & & Tray spacing (m) & 0.6096 & 0.6096 \\
\hline \multirow[t]{10}{*}{$\mathrm{C} 1$} & sizes & Diameter (m) & 6.40 & 5.47 \\
\hline & & stages & 34 & 33 \\
\hline & & QC (MW) & 42.5169 & 39.0000 \\
\hline & & $\mathrm{AC}(\mathrm{m} 2)$ & 3590.11 & 3293.00 \\
\hline & & QR (MW) & 29.5703 & 38.2000 \\
\hline & & $\operatorname{AR}\left(\mathrm{m}^{2}\right)$ & 1495.99 & 1932.00 \\
\hline & capital costs & Shell cost $\left(10^{6} \$\right)$ & 1.8090 & 1.5300 \\
\hline & & $\mathrm{HX} \operatorname{cost}\left(10^{6} \$\right)$ & 3.0010 & 3.0930 \\
\hline & & Total capital $\left(10^{6} \$\right)$ & 5.1163 & 4.623 \\
\hline & energy & Energy cost $\left(10^{6} \$ / y\right)$ & 3.3616 & 4.2810 \\
\hline \multirow[t]{10}{*}{$\overline{\mathrm{C} 2}$} & sizes & Diameter $(\mathrm{m})$ & - & 4.2 \\
\hline & & stages & - & 8 \\
\hline & & QC (MW) & - & 24.5 \\
\hline & & $\mathrm{AC}\left(\mathrm{m}^{2}\right)$ & - & 2065 \\
\hline & & QR (MW) & 10.5909 & 19.5000 \\
\hline & & $\operatorname{AR}\left(m^{2}\right)$ & 535.90 & 985.00 \\
\hline & capital costs & Shell cost $\left(10^{6} \$\right)$ & - & 0.3390 \\
\hline & & $H X \operatorname{cost}\left(10^{6} \$\right)$ & 0.4136 & 1.6900 \\
\hline & & Total capital $\left(10^{6} \$\right)$ & 0.4136 & 2.0200 \\
\hline & energy & Energy cost $\left(10^{6} \$ / y\right)$ & 0.01558 & 2.8900 \\
\hline \multirow[t]{10}{*}{$\mathrm{C} 3$} & sizes & Diameter $(\mathrm{m})$ & 3.45 & 6.20 \\
\hline & & stages & 5 & 8 \\
\hline & & QC (MW) & 8.3205 & 20.2000 \\
\hline & & $\mathrm{AC}\left(\mathrm{m}^{2}\right)$ & 460.20 & 1703.00 \\
\hline & & QR (MW) & 10.4016 & 27.2000 \\
\hline & & $\mathrm{AR}\left(\mathrm{m}^{2}\right)$ & 609.60 & 1374.00 \\
\hline & capital costs & Shell cost $\left(10^{6} \$\right)$ & 0.1723 & 0.5080 \\
\hline & & $H X \operatorname{cost}\left(10^{6} \$\right)$ & 1.1093 & 0.3040 \\
\hline & & Total capital $\left(10^{6} \$\right)$ & 1.2816 & 2.2300 \\
\hline & energy & Energy cost $\left(10^{6} \$ / y\right)$ & 1.3230 & 4.0300 \\
\hline \multirow[t]{2}{*}{ Heater 1} & & Exchange duty (MW) & 0.4650 & - \\
\hline & & $\mathrm{HX}$ cost $\left(10^{6} \$\right)$ & 0.07297 & - \\
\hline \multirow[t]{2}{*}{ Heater2 } & & Exchange duty (MW) & 0.4801 & - \\
\hline & & $\mathrm{HX}$ cost $\left(10^{6} \$\right)$ & 0.0745 & - \\
\hline Heater3 & & Exchange duty (MW) & 1.0302 & - \\
\hline
\end{tabular}




\begin{tabular}{llll}
\hline & HX cost $\left(10^{6} \$\right)$ & 0.1224 & - \\
\hline total capital & $(106 \$)$ & 8.3029 & 8.8730 \\
total energy & $(106 \$ / y)$ & 5.7080 & 11.2000 \\
TAC & $(106 \$ / y)$ & 7.3575 & 13.0400 \\
Exergy loss & $(\mathrm{MW})$ & 4.8540 & 9.3780 \\
\hline
\end{tabular}

HX represents total capital cost of heat transfer.

Table 7 also provides a head-to-head comparison of economics and exergy loss between the proposed TAME process and the existing TAME process. It can be observed that while the TAC of $\$ 13.0400$ million/year is required for the existing TAME production process using RD, it is only $\$ 7.3575$ million/year for the proposed TAME production process using RDWC. Consequently, a significant cost reduction in TAC by $43.58 \%$ using RDWC is achieved with a reduction in the total capital cost by $6.43 \%$. The total energy cost (i.e., operating cost) is reduced by $49.04 \%$ using RDWC compared to that using RD. This significant reduction mainly comes from significant decrease of the reflux ratio and significant reduction of heat duties in reboiler and heat exchangers using the proposed TAME production process. The reduction in energy requirements is mainly because the remixing is reduced with the presence of the diving wall inside the column. ${ }^{36-39}$ Overall, the proposed TAME process using RDWC is superior to the existing RD process with higher energy savings and lower capital cost as well as lower exergy loss.

\section{OVERALL CONTROL STRATEGY AND VALIDATION}

The steady-state optimization results in previous sections are exported to Aspen Dynamics ${ }^{\mathrm{TM}}$. The reflux drum of RDWC and iC5 recovery columns are all sized with 10 min holdup with 50\% liquid level. Pressure-driven simulation in Aspen Dynamics ${ }^{\mathrm{TM}}$ is used. While the top pressure of the RDWC is set at 4.0 bar to allow some pressure drop in the condenser, the top pressure of the iC5 recovery column is set to be 10.0 bar. The pressure drops inside the two columns are automatically calculated in Aspen Dynamics ${ }^{\mathrm{TM}}$ to account for liquid hydraulics and vapor traffic. The bottom pressures of the RDWC and iC5 recovery columns are calculated to be 4.35 bar and 10.27 bar, respectively. The values of side weirs and other parameters are defaults of Aspen Plus ${ }^{\circledR}$ and Aspen 
Dynamics $^{\mathrm{TM}}$ simulator.

\subsection{Proposed Control Strategy}

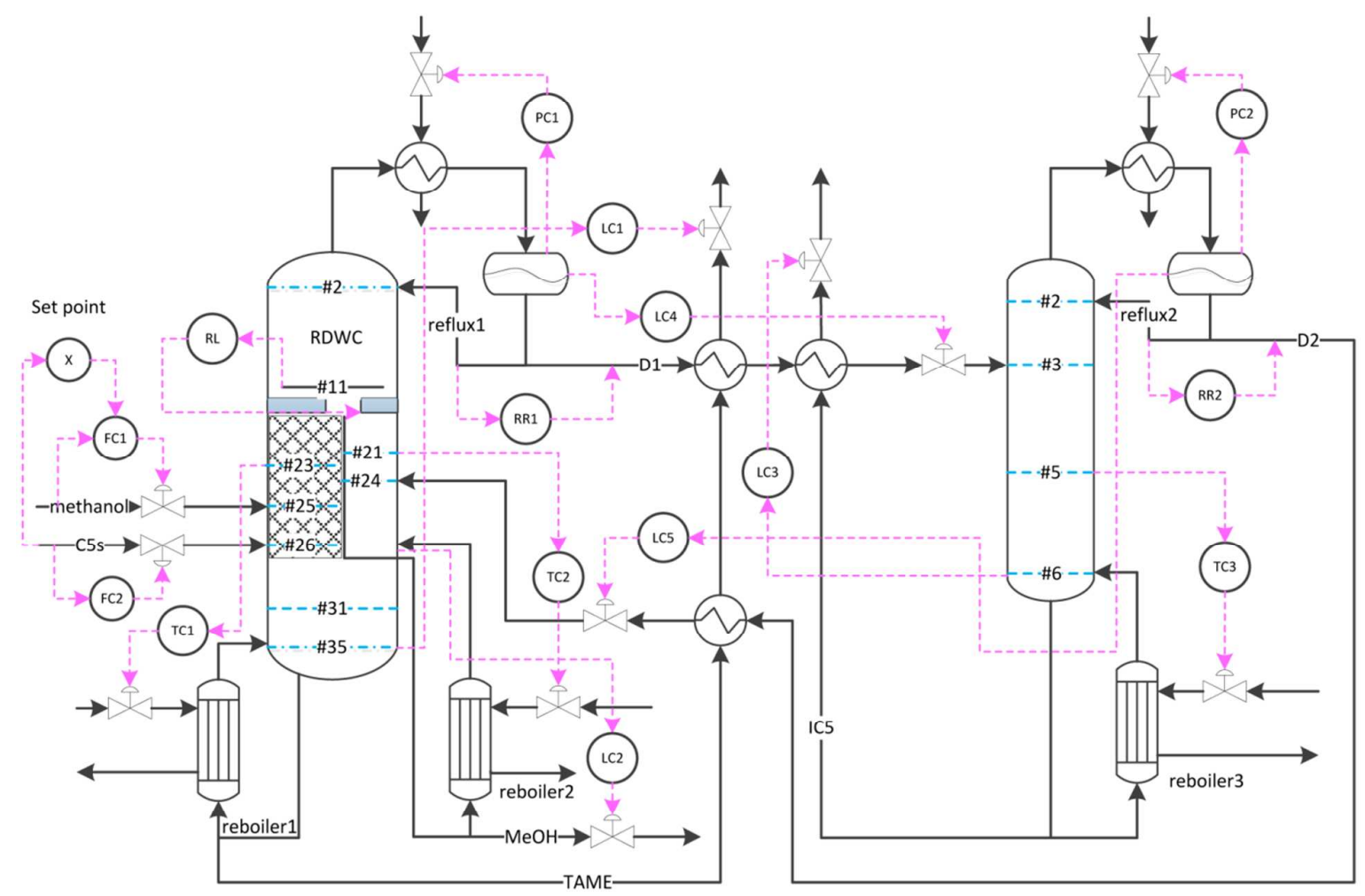

Figure 13. Proposed overall control strategy for TAME production using RDWC and pressure swing columns.

The overall control strategy for the proposed TAME production using integrated RDWC and pressure swing columns is illustrated in Figure 13. All operating parameters such as feed rates, and liquid split ratio are controlled at (or close to) their set-points when disturbances occur. For instance, the feed ratio of $\mathrm{C} 5 \mathrm{~s}$ and methanol is controlled to be the set-point (denoted as X) resulting in quick adjustment of methanol feed rate when some disturbance in $\mathrm{C} 5 \mathrm{~s}$ feed flow takes place. The liquid split ratio is controlled to its set-point to guarantee specified product purities. The liquid levels at the bottom of RDWC are controlled by manipulating the flow rates of TAME and methanol (see LC1 and LC2). The bottom level in the iC5 recovery column is controlled by manipulating the bottom product iC5s flowrate (LC3). The liquid level in the reflux drum is controlled by adjusting 
the flow rates of top products (LC4 and LC5). The reflux ratios are controlled to their set-points to help the separation. The sensitive stage temperatures in the two columns are controlled by manipulating the reboiler heat input (TC1, TC2, and TC3). The top pressures in the two columns are controlled to their set-points by adjusting the feed flow rates of the cooling water in the condensers (see PC1 and PC2).

\subsection{Determination of Tray Temperature Control Points}
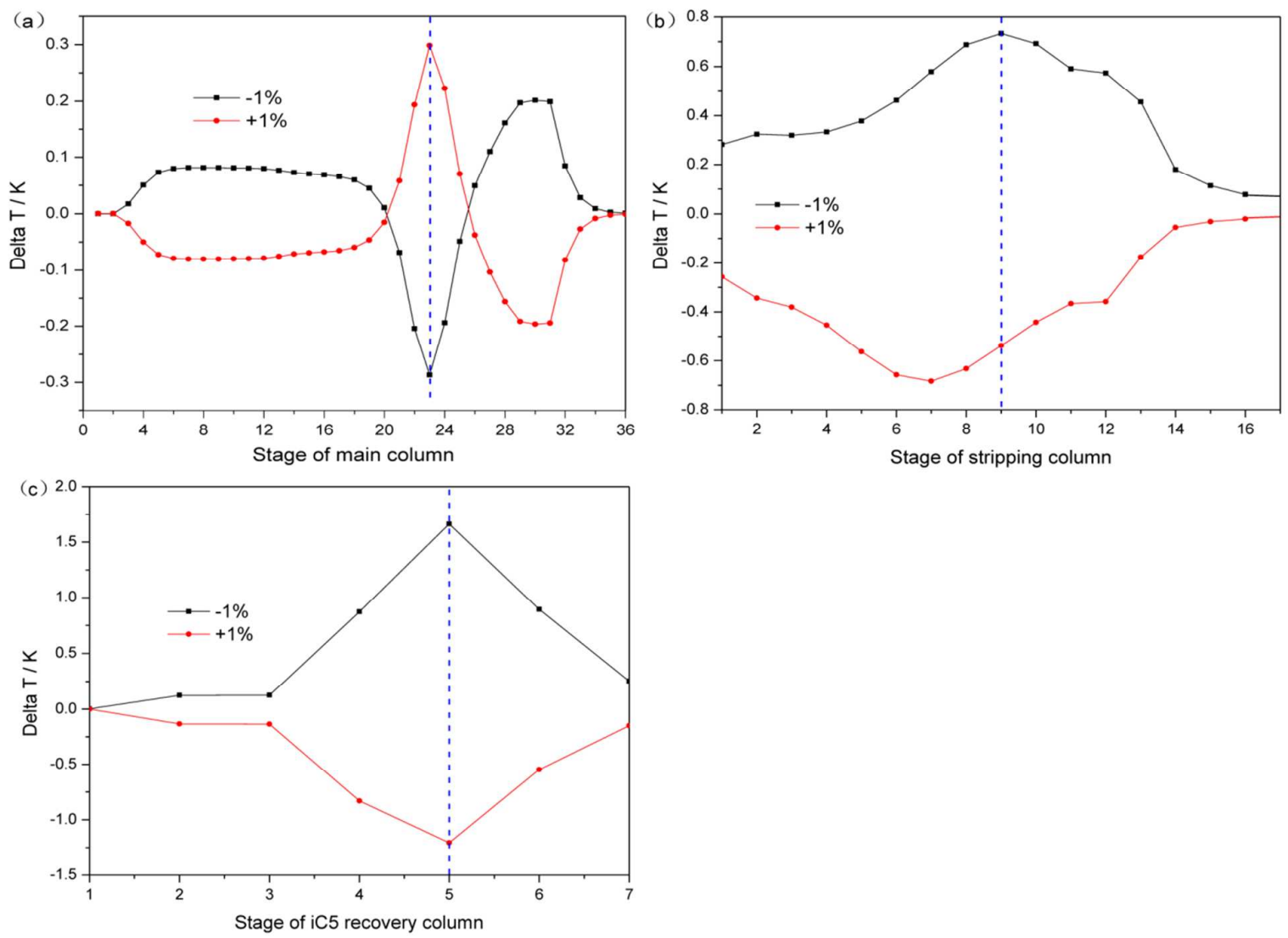

Figure 14. Schematic diagram of tray temperature variations when reboiler duty changes by $1 \%$ in (a) main column, (b) stripping column, and (c) iC5 recovery column.

Figure 14 shows tray temperature variations in the RDWC and iC5 recovery columns when their reboiler heat duties deviate from their nominal values by $1 \%$. From Figure 14, we observe the tray temperature in a column varies with its reboiler heat duty changes. The temperature variation reaches its maximum at stage $\# 23$ and $\# 21$ in RDWC and stage $\# 5$ in the iC5 recovery column, 
demonstrating they are highly sensitive to the reboiler heat duty. Note that the stage \#9 in the stripping column in RDWC is equivalent to the stage \#21 in RDWC since the main column and the stripping column in RDWC share 12 rectifying stages.

\subsection{Dynamic Simulation}

Dynamic simulation is carried out in Aspen Dynamics ${ }^{\mathrm{TM}}$ simulator to show the effectiveness of our proposed control strategy in response to disturbances in feed rates and feed compositions. The proportional-integral (PI) controllers are used for liquid level, flow, pressure control, and tray temperature. Normally, the feed flow can be measured and controlled within several seconds. Therefore, the integral time for the feed flow controller is usually set as $0.3 \mathrm{~min} .{ }^{32}$ Due to the noisy signal from the flow measurement devices, the gain value of the controller should be set at an appropriate size, usually $K_{\mathrm{C}}=0.5 .^{32}$ The pressure controller parameters $\tau_{1}=20$ min and $K_{\mathrm{C}}=12$ min are default values in Aspen Dynamics ${ }^{\mathrm{TM}}$ simulator. $^{22}$

We use the tuning method Treus-Luyben implemented in Aspen Dynamics ${ }^{\mathrm{TM}}$ simulator to calculate the gain $K_{C}$ and integral time $\tau_{1}$ for a tray temperature PI controller as given in eqs. 26-27.

$$
\begin{aligned}
& K_{C}=K_{U} / 3.2 \\
& \tau_{1}=2.2 P_{U}
\end{aligned}
$$

where, the values of $K_{U}$ and $P_{U}$ are generated by the Aspen simulator automatically. The tuning parameters for the three tray temperature controllers are shown in Table 8.

Table 8. Gain and integral time for tray temperature controller using Tyreus-Luyben tuning methods.

\begin{tabular}{llll}
\hline & TC1 & TC2 & TC3 \\
\hline $\mathrm{K}_{\mathrm{C}}$ & 3.25 & 5.38 & 3.87 \\
$\tau_{1}$ & 19.8 & 13.2 & 5.94 \\
\hline
\end{tabular}

Figures 15a-i illustrate the dynamic simulation results when disturbances in feed flow rates by $20 \%$ take place at $\mathrm{t}=2 \mathrm{hr}$. In Figures $15 \mathrm{~g}-\mathrm{i}$, Temperature 1, Temperature 2, and Temperature 3 
represent the control temperatures in main column, stripping column, and iC5 recovery column, respectively. These temperatures are the key controlled variables to guarantee the product purity. While blue solid lines represent the responses to increases in the feed rate by $20 \%$, red dash lines are responses to decreases in the feed rate by $20 \%$.
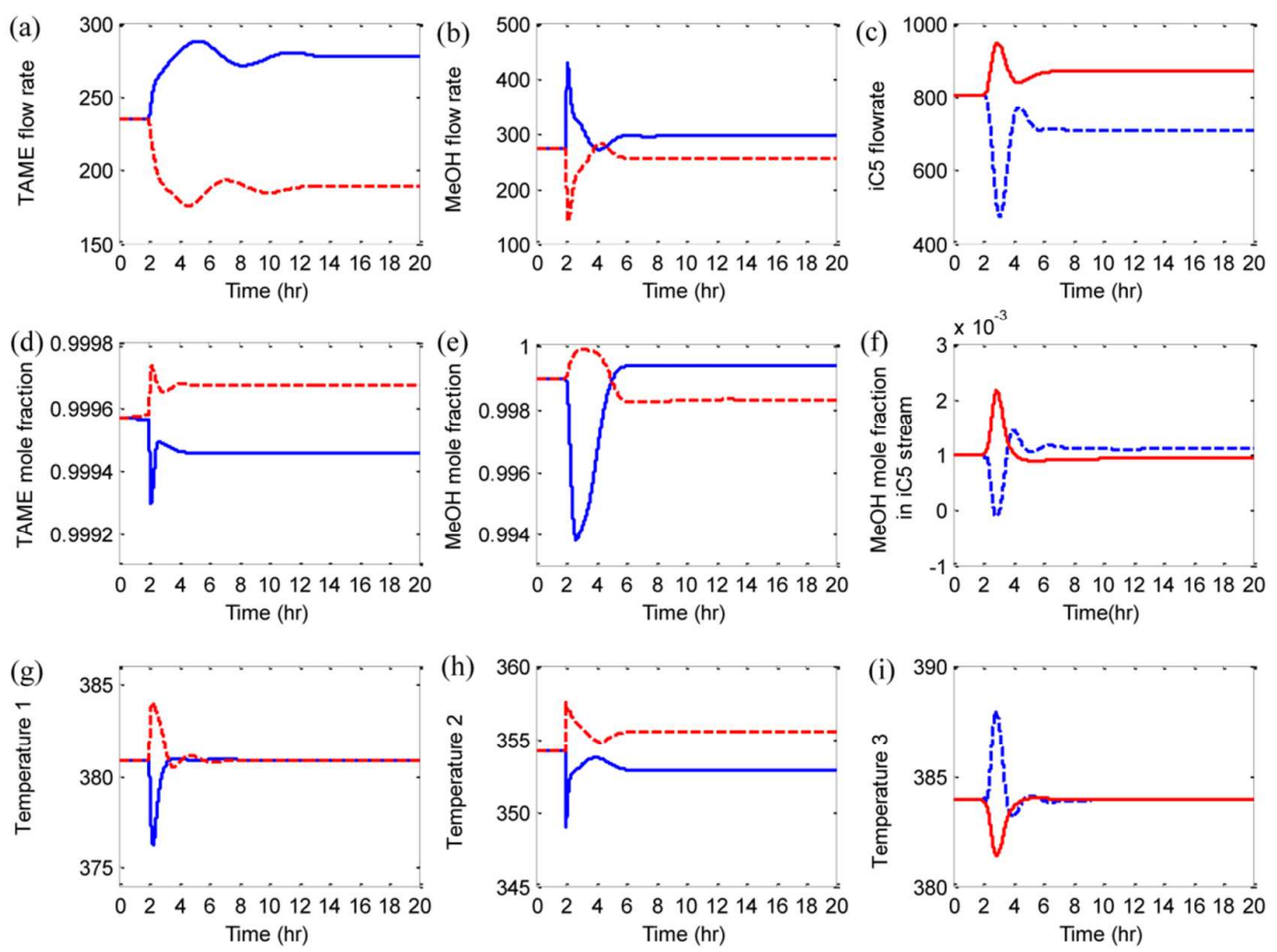

Figure 15. Closed-loop dynamic simulation results with feed flow rate disturbances by $20 \%$.

From Figure 15, it can be observed that a new steady state is reached after 2 hours when a disturbance in feed flow rates occurs at $t=2 \mathrm{hr}$. At the new steady state, the purities of TAME and methanol in RDWC are $99.9457 \mathrm{~mol} \%$ and $99.8330 \mathrm{~mol} \%$ respective corresponding to increase in feed flow rate by $20 \%$, whilst they are $99.9672 \mathrm{~mol} \%$ and $99.9420 \mathrm{~mol} \%$ respectively corresponding to decrease in feed flow rate by $20 \%$. Under the increase and decrease in feed flow rate, the purities of TAME and methanol at the new steady state are controlled to be very close to their optimal values of $99.9580 \mathrm{~mol} \%$ and $99.9000 \mathrm{~mol} \%$. Likewise, with two disturbances in feed flow rates, the methanol mole fractions at the bottom of iC5 recovery column are controlled to be 
$0.1753 \mathrm{~mol} \%$ and $0.1103 \mathrm{~mol} \%$, which are very close to the mole fraction constraint of $0.1 \mathrm{~mol} \%$ in iC5 recovery stream. Similarly, the controlled tray temperatures can return close to their set-points. For instance, the controlled tray temperature in the main column of RDWC returns to $380.868 \mathrm{~K}$ within 2 hours as shown in Figure 15g, which is very close to its optimal temperature of $380.867 \mathrm{~K}$.
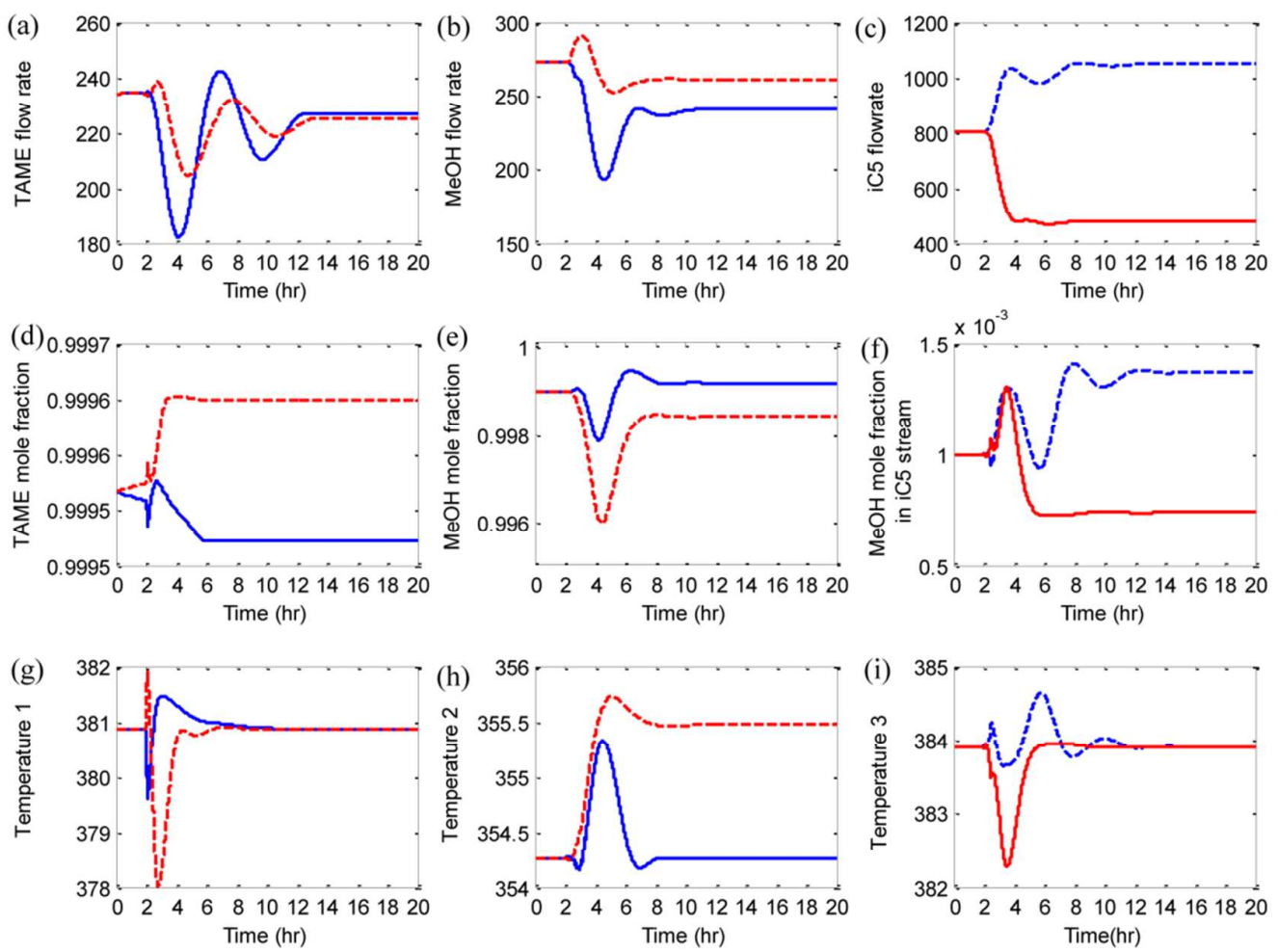

Figure 16. Closed-loop dynamic simulation results with feed composition disturbances by $10 \%$.

Figures 16a-i present dynamic simulation results when disturbances in feed compositions by $10 \%$ take place at $\mathrm{t}=2 \mathrm{hr}$. While the blue solid lines show the responses to increase in iC5 mole compositions from $40.8296 \mathrm{~mol} \%$ to $50.8296 \mathrm{~mol} \%$, the red dash lines represent the responses to decrease of iC5 mole composition from 40.8296 mol\% to 30.8296 mol\%. From Figures 16a, 16d and $16 \mathrm{~g}$, it can be observed that the TAME purity and tray temperature in the main column of RDWC can return to a new steady state within 4 hours after disturbances start whilst the TAME production rate returns to a new steady state within 10 hours. The new TAME purities are about $99.9512 \mathrm{~mol} \%$ and $99.9650 \mathrm{~mol} \%$, which are close to its set-point of $99.9580 \mathrm{~mol} \%$. The new tray 
temperatures are 354.17 and $355.47 \mathrm{~K}$, which are almost the same as the set-point of $354.26 \mathrm{~K}$. Similar observations can be made for methanol and iC5 from Figures 16b-d, 16e-f, and 16h-i.

As shown in Figures 15 and 16, the proposed control strategy can be well applied to RDWC with a divided-wall at the top of the column for separating azeotrope mixtures. It can also be applied to azeotrope dividing wall column with a divided-wall at the top of the column for separating binary azeotropic mixtures because it also involves a liquid split ratio (i.e., $\mathrm{R}_{\mathrm{L}}$ ) existing in the sharing rectifying section. However, the proposed strategy may not be qualified for the extractive dividing wall column with a divided-wall at the top of the column and the conventional dividing wall column with a divided-wall located (or close) in (to) the middle of the column because the vapor split ratio (i.e., $\mathrm{R}_{\mathrm{V}}$ ) are required in the sharing stripping section which has been not studied in this work. To maintain the product purity using a normal distillation column, it is not necessary to adopt such complex control strategy. However, the proposed effective control strategy is able to provide a theoretical guideline for control of extractive dividing wall columns, conventional dividing wall columns, and basic distillation columns.

\section{CONCLUSIONS}

In this paper, we developed a novel process for TAME production using integrated RDWC and pressure swing distillation columns. Then, we proposed a systematic procedure for optimal design of the proposed TAME production process, which involved thermodynamic topologic insight and residue curve maps analysis, and process optimization through sensitivity analysis tool implemented in Aspen Plus ${ }^{\circledR}$. The total annualized cost and exergy loss analysis demonstrates the optimal TAME production process using integrated RDWC and pressure swing columns could achieve $43.58 \%$ reduction in total annualized cost and $48.24 \%$ reduction in exergy loss compared to the existing TAME production process using reactive distillation. An overall control strategy including flow rate control loop, liquid level control loop, pressure control loop, and tray temperature control loop was proposed to make sure liquid levels, flow rates and tray temperatures 
in the process are controlled at or close to their set-points when disturbances in feed occur. The dynamic simulation results in Aspen Dynamics ${ }^{\mathrm{TM}}$ show that a new steady state at or close to the optimal conditions could be reached within a desired time after disturbances happen using the proposed control strategy. The TAME product purity could be well controlled to be within the desired purity.

Although the optimal TAME production and methanol recovery process through integrated RDWC and pressure swing columns has been generated through sensitivity analysis tool in Aspen Plus $^{\circledR}$, global optimality may not be reached through the sensitivity analysis tool. Therefore, our future work is to develop a systematic approach to identify effective lower and upper bounds and investigate different optimization methods such as stochastic optimization methods and deterministic global optimization methods to improve the design with further potential reduction in total annualized cost and exergy loss.

The proposed process and systematic procedure is also applicable for other etherification synthesis such as MTBE production and esterification synthesis such as n-amyl acetate and n-hexyl acetate production. It may be also applicable to the chemicals production involving reactions in the liquid phases and reaction temperature to be equal to the bubble point at specified tray of distillation column, such as formic acid production from saponification, acetic acid production from hydrolysis, bromoethane production from halogenation, and nitrobenzene production from nitrification. It is worthwhile to note that the proposed process and procedure may not be extended to the systems involving reactions to take place in vapor phase or at a very higher temperature.

\section{Supporting Information}

Binary parameters (Table S1)

This information is available free of charge via the Internet at http://pubs.acs.org/.

\section{Acknowledgment}


1

2

3

4

5

6

7

8

9

10

We acknowledge the financial support provided by the National Natural Science Foundation of China (No.21606026); the National Key Research and Development Program (No.2017YFB0603105); the Natural Science Foundation of Chongqing, China (No.CSTC2016JCYJA0474); the Fundamental Research Funds for the Central Universities (No.106112017CDJQJ228809); and Hundred Talents Program at Chongqing University. Helpful comments and suggestions from the paper reviewers are also gratefully acknowledged.

\section{NOMENCLATURE}

TAME $=$ Tertiary-Amyl Methyl Ether

$\mathrm{RDWC}=$ reactive dividing-wall column

$\mathrm{RD}=$ reactive distillation

$\mathrm{RCMs}=$ residue curve maps

MTBE $=$ Methyl Tert-Butyl Ether

DWC $=$ dividing wall column

2M1B = 2-methyl-1-butene

2M2B = 2-methyl-2-butene

$\mathrm{MeOH}=$ methanol

VLE $=$ vapor liquid equilibrium

$\mathrm{R}_{\mathrm{L}}=$ liquid split ratio

$\mathrm{R}_{\mathrm{V}}=$ vapor split ratio

$\mathrm{R}=$ reflux ratio

$\varphi=$ boilup ratio

$\mathrm{N}_{\mathrm{FE}}=\mathrm{MeOH}$ feed stage

$\mathrm{N}_{\mathrm{Fl}}=$ main feed stage of RDWC column

$\mathrm{N}_{\mathrm{FA}}=$ azeotropes recycle feed stage

$\mathrm{N}_{\mathrm{F} 2}=$ main feed stage of iC5 recovery column

$\mathrm{N}_{\mathrm{T} 1}=$ total number of stages of main column in RDWC

$\mathrm{N}_{\mathrm{T} 2}=$ total number of stages of stripping column in RDWC

$\mathrm{N}_{\mathrm{T} 3}=$ total number of stages of iC5 recovery column

$\mathrm{Ex}=$ exergy

$\mathrm{El}=$ exergy loss

$\mathrm{H}=$ enthalpy

$\mathrm{S}=$ entropy

$\mathrm{TAC}=$ annual operating cost 


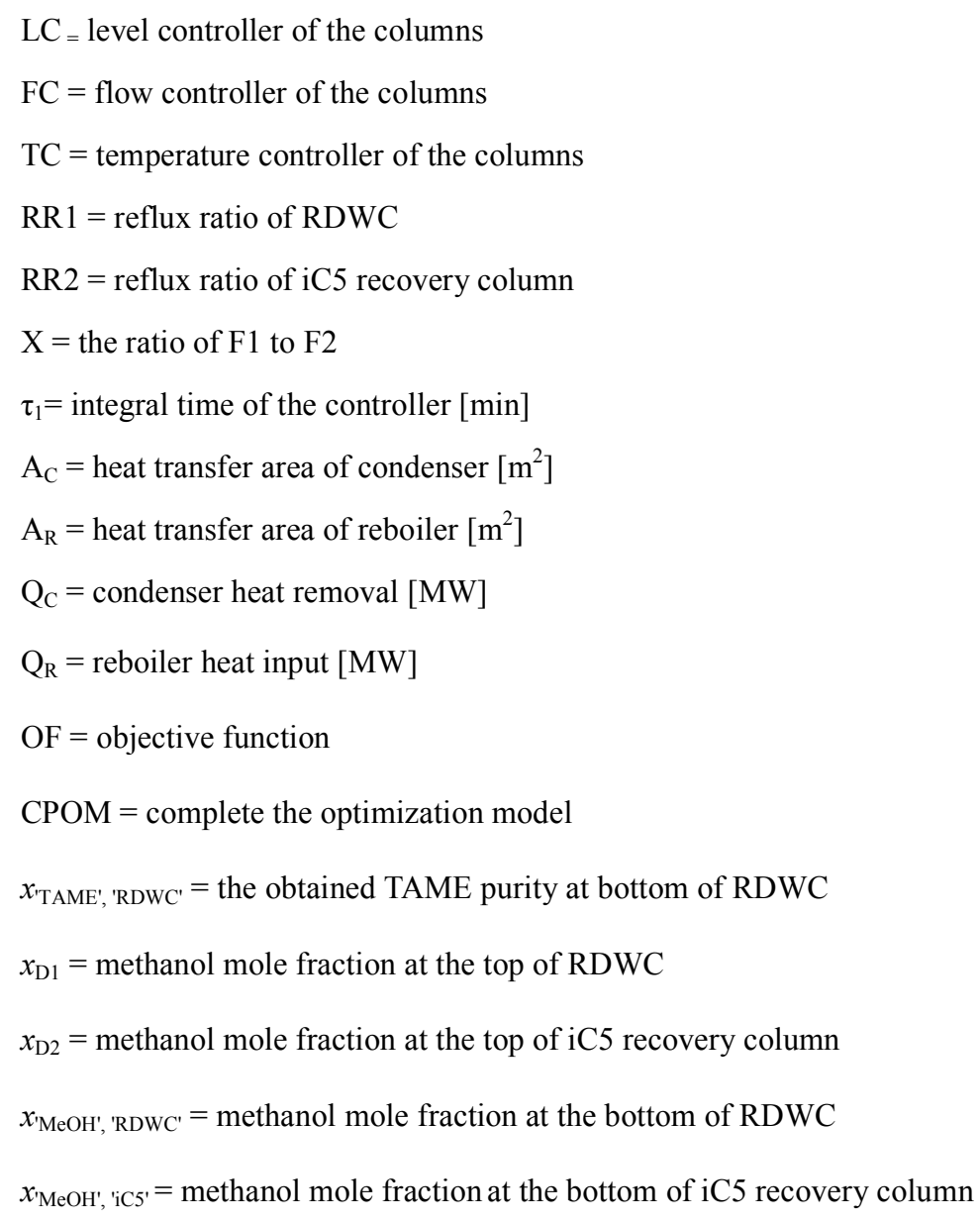




\section{CITED LITERATURES}

1. Wu, Y. C.; Chien, I. L. Two-Stripper/Decanter Flowsheet for Methanol Recovery in the TAME Reactive-Distillation Process. Ind. Eng. Chem. Res. 2009, 48, (23), 10532-10540.

2. Kiviranta-Pääkkönen, P.; Struckmann, L.; Krause, A. O. I. Comparison of the Various Kinetic Models of TAME Formation by Simulation and Parameter Estimation. Chem. Eng. Technol. 1998, 21, (21), 321-326.

3. Al-Arfaj, M. A.; Luyben, W. L. Plantwide control for TAME production using reactive distillation. AIChE J. 2004, 50, (7), 1462-1473.

4. Luyben, W. L.; Yu, C. C. Reactive distillation design and control: John Wiley \& Son, 2009.

5. Oktar, N.; Murtezaoglu, K.; Dogu, T.; Dogu, G. Dynamic Analysis of Adsorption Equilibrium and Rate Parameters of Reactants and Products in MTBE, ETBE and TAME Production. Canadian J. Chem. Eng. 1999, 77, (2), 406-412.

6. Hwang, W. S.; Wu, J. C. Kinetics and Thermodynamics of Synthesis of Tertiary-Amyl Methyl Ether Catalyzed by Ion-Exchange Resin. J. Chin. Chem. Soc-Taip. 1994, 41, (2), 181-186.

7. Rihko, L. K.; Kiviranta-Paeaekkoenen, P. K.; Krause, A. O. I. Kinetic Model for the Etherification of Isoamylenes with Methanol. Ind. Eng. Chem. Res. 1997, 36, (3), 614-621.

8. Lovisi, H. R.; Piccoli, R. L. Kinetic and Thermodynamic Study of the Liquid-Phase Etherification of Isoamylenes with Methanol. Ind. Eng. Chem. Res. 1995, 34, (34), 510-515.

9. Rihko, L. K.; Krause, A. O. I. Kinetics of Heterogeneously Catalyzed tert-Amyl Methyl Ether Reactions in the Liquid Phase. Ind. Eng. Chem. Res. 1995, 34, (4), 1172-1180.

10. Oost, C.; Hoffmann, U. The Synthesis of tertiary Amyl Methyl Ether (TAME): microkinetics of the reactions. Chem. Eng. Sci. 1996, 51, (3), 329-340.

11. Boza, N.; Dogua, T.; Murtezaoglu, K.; Dogu, G. Effect of hydrogen ion-exchange capacity on activity of resin catalysts in tert-amyl-ethyl-ether synthesis. Applied Catalysis A: General. 2004, 268, (1-2), 175-182.

12. Päivi Pääkkönen K. K.; Linnekoski, J. A.; Krause, A. O. I. Dehydration of the Alcohol in the Etherification of Isoamylenes with Methanol and Ethanol. Ind. Eng. Chem. Res. 1998, 37, (1), 18-24.

13. Stankiewicz, A.; Moulijn, J. A. Process intensification. Ind. Eng. Chem. Res. 2002, 41, 1920-1924.

14. Kiss, A. A.; Bildea, C. S. Integrated reactive absorption process for synthesis of fatty esters. Bio. Technol. 2011, 102, (2), 490-498.

15. Subawalla, H.; Fair, J. R. Design guidelines for solid-catalyzed reactive distillation systems. Ind. Eng. Chem. Res. 1999, 38, (10), 3696-3709.

16. Sun, L. Y.; Chang, X. W.; Qi, C. X.; Li, Q. S. Implementation of Ethanol Dehydration Using Dividing-Wall Heterogeneous Azeotropic Distillation Column. Sep. Sci. Technol. 2010, 46, (8), 1365-1375.

17. Asprion, N.; Kaibel, G. Dividing wall columns: Fundamentals and recent advances. Chem. Eng. \& Pro.: Process Intensification. 2010, 49, (2), 139-146.

18. Zheng, L.; Cai, W. F.; Zhang, X. B.; Wang, Y. Design and control of reactive dividing-wall column for the synthesis of diethyl carbonate. Chem. Eng. Pro. 2017, 111, 127-140.

19. Dejanović, I.; Matijašević, L.; Olujić, Ž. Dividing wall column-A breakthrough towards sustainable distilling. Chem. Eng. Pro. 2010, 49, (6), 559-580.

20. Madenoor Ramapriya, G.; Tawarmalani, M.; Agrawal, R. Thermal Coupling Links to Liquid-Only Transfer Streams: A Path for New Dividing Wall Columns. AIChE J. 2014, 60, (8), 2949-2961.

21. Luyben, W. L.; Ling, H. Temperature Control of the BTX Divided-Wall Column. Ind. Eng. Chem. Res. 2010, 49, (1), 189- 203.

22. Li, L. M.; Guo, L. J.; Tu, Y. Q.; Yu, N.; Sun, L. Y.; Tian, Y. Y.; Li, Q. S. Comparison of different extractive distillation processes for 2-methoxyethanol/toluene separation: design and control. Comp. Chem. Eng. 2017, 99, 117-134.

23. Luyben, W. L. Control of an azeotropic DWC with vapor recompression. Chem. Eng. Process. 2016, 109, $114-124$.

24. Kiss, A. A. Novel process for biodiesel by reactive absorption. Sep. Purif. Technol. 2009, 69, (3), $280-287$.

25. Wu, Y. C.; Lee, H. Y.; Lee, C. H.; Huang, H. P.; Chien, I. L. Design and Control of Thermally-Coupled Reactive Distillation System for Esterification of an Alcohol Mixture Containing n $\square$ Amyl Alcohol and n $\square$ Hexanol. Ind. Eng. Chem. Res. 2013, 52, (48), 17184-17197.

26. Gómez-Castro, F. I.; Segovia-Hernández, J. G.; Rico-Ramireza, V.; Hernández, S. Feasibility study of a thermally coupled reactive distillation process for biodiesel production. Chem. Eng. \& Pro.: Process Intensification. 2010, 49, (3), 262-269. 
27. Bumbac, G.; Pleşu, A. E.; Pleşu, V. Reactive Distillation Process Analysis in a Divided Wall Column. European Symposium on Comp. Aided Chem. Eng. 2007, 24, (7), 443-448.

28. Kang, D.; Lee, J. W. Graphical Design of Integrated Reaction and Distillation in Dividing Wall Columns. Ind. Eng. Chem. Res. 2015, 54, (12), 3175-3185.

29. Shen, W. F.; Dong, L. C.; Wei, S. A.; Li, J.; Benyounes, H.; Gerbaud, V.; You, X. Q. Systematic Design of an Extractive Distillation for Maximum-Boiling Azeotropes with Heavy Entrainers. AIChE J. 2015, 61, (11), 3898-3910.

30. Shen, W. F.; Hassiba, Benyounes; Vincent, Gerbaud. Extractive distillation: recent advances in operation strategies. Rev. Chem. Eng. 2015, 31, (1), 13-26.

31. Douglas, J. M. Conceptual design of chemical processes. McGraw-Hill: New York, 1988.

32. Luyben, W. L. Plantwide Dynamic Simulators in Chemical Processing and Control. Marcel Dekker: New York, 2002.

33. Nova-Rincón, A.; Ramos, M.; Gomez, J. M. Simultaneous optimal design and operation of a diabatic extractive distillation column based on exergy analysis. Int. J. Exergy. 2015, 17, 287-312.

34. Carrera-Rodríguez, M., Segovia-Hernández, J.G., Hernández-Escoto, H., Hernández, S., Bonilla-Petriciolet, A. A Note on an Extended Short-Cut Method for the Design of Multicomponent Reactive Distillation Columns. Chem. Eng. Res. \& Des. 2014, 92, (1), 1-12.

35. Jaime - Leal, J.E., Bonilla - Petriciolet, A., Segovia - Hernández, J.G., Hernández, S., Hernández - Escoto, H. On the Multiple Solutions of the Reactive Distillation Column for Production of Fuel Ethers, Chem. Eng. \& Pro.: Process Intensification. 2013, 72, (5), 31-41.

36. Sangal, V.K., Kumar, V., Mishra, I.M. Divided wall distillation column: rationalization of degree of freedom analysis. Theor. Found. Chem. Eng. 2012, 46, (4), 319-328.

37. Sotudeh, N., Shahraki, B.H. A method for the design of divided wall columns. Chem. Eng. Tech. 2010, 30, (9), 1284-1291.

38. Isopescu, R., Woinaroschy, A., Draghiciu, L. Energy reduction in a divided wall distillation column. Rev. Chim. 2008, 59, (7), 812-815.

39. Jasdeep, K., Vikas, K. S. Reducing energy requirements for ETBE synthesis using reactive dividing wall distillation column. Energy. 2017, 126, 671-676. 


1
2
3
4
5
6
7
8
9
10
11
12
13
14
15
16
17
18
19
20
21
22
23
24
25
26
27
28
29
30
31
32
33
34
35
36
37
38
39
40
41
42
43
44
45
46
47
48
49
50
51
52
53
54
55
56
50

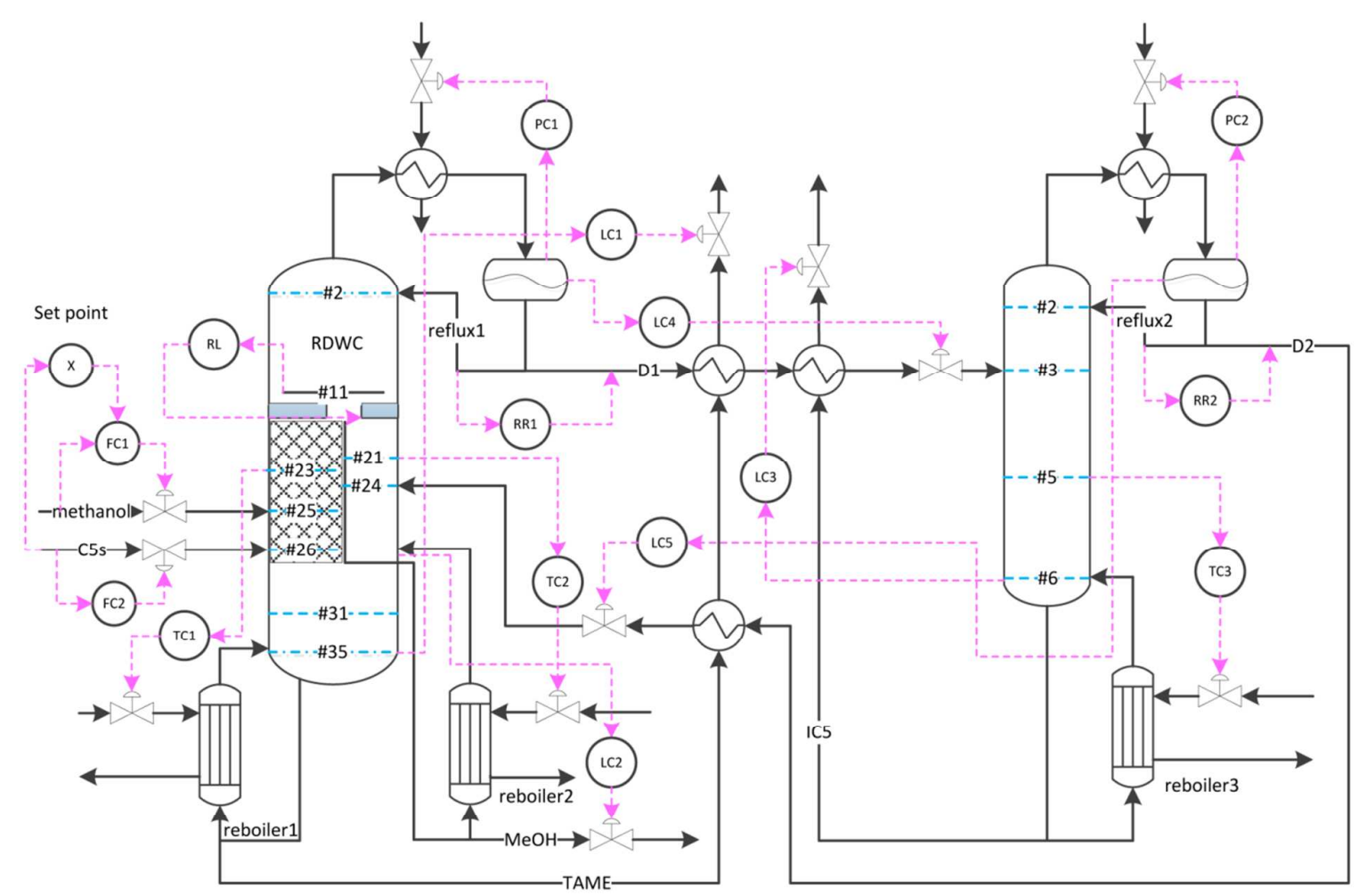

For Table of Contents Only 